\title{
Dynamic niches in the origination and differentiation of haematopoietic stem cells
}

\author{
Leo D. Wang ${ }^{2,3,4}$ and Amy J. Wagers ${ }^{1,2,3}$ \\ ${ }^{1}$ Howard Hughes Medical Institute \\ ${ }^{2}$ Department of Stem Cell and Regenerative Biology, Harvard University, Harvard Stem Cell \\ Institute, 7 Divinity Ave., Cambridge, MA 02138 \\ 3Joslin Diabetes Center, One Joslin Place, Boston, MA 02215 \\ ${ }^{4}$ Dana Farber/Children's Hospital Cancer Center, Boston, MA 02215
}

\section{Abstract}

Haematopoietic stem cells (HSCs) are multipotent, self-renewing progenitors that generate all mature blood cells. HSC function is tightly controlled to maintain haematopoietic homeostasis, and this regulation relies on specialized cells and factors that constitute the haematopoietic 'niche', or microenvironment. Recent discoveries, aided in part by technological advances in in vivo imaging, have engendered a new appreciation for the dynamic nature of the niche, identifying novel cellular and acellular niche components and uncovering fluctuations in the relative importance of these components over time. These new insights significantly improve our understanding of haematopoiesis and raise fundamental questions about what truly constitutes a stem cell niche.

\section{Introduction}

In adult humans, haematopoietic stem cells (HSCs) are responsible for generating $\sim 1 \times 10^{9}$ red blood cells and $\sim 1 \times 10^{8}$ white blood cells every hour, including a full complement of platelets and other mature blood lineages. HSCs must also self-renew, and thus must constantly integrate and respond to myriad external inputs to maintain haematopoietic homeostasis. HSCs typically are depicted at the top of a hierarchical "lineage tree", each branch point of which indicates a restriction in developmental potential (Fig. 1).

During mammalian development, haematopoiesis occurs in sequential stages: first primitive, and then definitive blood formation. These stages are temporally and anatomically distinct, invoking unique cellular and molecular regulators. The formation of primitive blood cells occurs early during fetal life, with coordinated progression from extraembryonic to intraembryonic sites of haematopoiesis. Within the embryo, definitive haematopoiesis undergoes developmentally stereotyped transitions; HSCs arising from the aorta-gonadmesonephros (AGM) region migrate first to the placenta and fetal liver, and then to the

Competing interests statement

The authors declare no competing financial interests. 
spleen. Eventually, haematopoiesis shifts to the bone marrow, where homeostatic blood formation is maintained postnatally.

As proposed initially by Schofield ${ }^{1}$ in his 1978 description of the regulation of blood formation in the marrow cavity, both primitive and definitive haematopoiesis require input from the cellular microenvironment, or 'niche'. When first proposed, this concept held that a stem cell must associate "with other cells which determine its behaviour" in order to "prevent its maturation" 1 loss of this association was hypothesized to result in differentiation. This idea has evolved, and the concept of the niche now includes specific cell types, anatomical locations, soluble molecules, signalling cascades and gradients, as well as physical factors such as shear stress, oxygen tension, and temperature ${ }^{2-7}$. Inputs from the niche can be permissive of, or conducive to, homeostatic HSC self-renewal and differentiation, but also may constrain normal haematopoiesis under pathological conditions such as myelodysplasia, aging, and haematologic malignancy. Yet, the definition of the niche as a microenvironment that provides spatially and temporally coordinated signals to support stem cell function has remained.

Niches were characterized initially in invertebrate model organisms, such as worms and flies $^{8-10}$, and subsequently identified in mammals using targeted genetic manipulations ${ }^{11-15}$. Our conception of the haematopoietic stem cell niche also has been informed by studies in non-haematopoietic tissues, such as the hair follicle, auditory hair cell, and intestinal crypt. In these tissues, clear spatial constraints make identification of niche components more straightforward than in the haematopoietic system, where blood cells are widely disseminated and constantly in motion ${ }^{16}$. This spatially-defined concept of the niche, which has been derived from anatomically static tissues, has been translated across organisms and tissue types, providing a generalized model for stem cell regulation. However, in certain cases, direct evidence that this model is applicable still is lacking. Nonetheless, it is widely accepted that niches exist in most, if not all, tissues, and that they provide both basic cellular necessities, such as mechanical support, trophic factors, and hospitable physical and chemical conditions, as well as stem cell-specific self-renewal and differentiation cues (Fig. 2).

Several new and elegant techniques and model systems have been applied to HSC development, permitting an improved functional and anatomical dissection of HSC interactions with the niche. In particular, real time in vivo imaging has enabled the direct visualization of HSCs and their niches, providing key insights into the origins, dynamics, and physiological regulation of the anatomic compartments in which HSCs reside. It is clear now that signals from a diversity of non-haematopoietic cell types play a coordinated part in ensuring proper HSC function. Moreover, although certain features appear to be common among niches that serve HSCs and those that serve non-HSCs, our improved understanding of the HSC niche underscores important distinctions from the niches found in solid tissues. In particular, haematopoietic niches may not be anatomically restricted, and the signals provided to HSCs may be spatially as well as temporally compartmentalized. Thus, altering either the location or the timing of niche-dependent signalling may initiate divergent developmental outcomes. 
In this Review, we discuss the HSC niche from an ontogenic perspective. We address current theories and open questions surrounding niche cells and their role in regulating fetal and adult definitive haematopoiesis. HSC biology is a rapidly expanding field, and recent advances have increased interest in the fundamental biology of these cells and in their potential as a source material for gene and cell therapy. Deeper understanding of the signals that stem cells receive from their niche as they grow and differentiate is essential for optimizing their therapeutic benefit.

\section{Vertebrate haematopoiesis}

Vertebrate haematopoiesis takes place in ontogenic waves. In both fish and mammals there are primitive phases, in which blood stem cells produce only a subset of specialized blood lineages, and definitive phases, in which true HSCs appear. In zebrafish, at least three distinct phases of haematopoietic development exist, and in mammals there are at least two. Primitive haematopoiesis is first detected extra-embryonically, in the yolk sac, as early as day e7.5 in mice and 30 days post-conception (pc) in humans ${ }^{17-19}$ (Fig. 3). Although evidence exists that cells isolated from the yolk sac can reconstitute haematopoiesis fully $^{20,21}$, it has recently become clear that multipotent HSCs also emerge directly from the AGM region (at day e10.5 in mice ${ }^{22,23}$ and 4 weeks pc (wpc) in humans ${ }^{24}$ ) to initiate definitive haematopoiesis. In all studied vertebrates, in fact, the first HSCs arise from the ventral wall of the dorsal aorta ${ }^{25-30}$, although they subsequently seed additional tissues and organs in a species-specific manner. In mammals, haematopoiesis moves from the AGM to the placenta and fetal liver; for example, by day e11-12 in mice and by $5 \mathrm{wpc}$ in humans. Haematopoiesis in mice shifts to the spleen by day e14 and begins to shift to the bone marrow by e18; in humans, it moves from the fetal liver to the bone marrow at $12 \mathrm{wpc}$. By birth in humans, the bone marrow supports the vast majority of haematopoiesis, and extramedullary multilineage haematopoiesis is negligible except in cases of pathology. By contrast, in mice, splenic haematopoiesis persists for several weeks postnatally ${ }^{31}$. Finally, in fish, the kidney serves as the predominant site of haematopoiesis in adult life.

The molecular underpinnings of the dynamic progression of blood cell formation during development are complex and still under investigation (see below). It is clear that many cytokines influence the differentiation and proliferation of haematopoietic stem and progenitor cells (HSPCs, a designation which includes both HSCs and multipotent and oligopotent progenitors). However, only a few have been demonstrated genetically to be necessary for HSC maintenance in vivo; these have been reviewed extensively elsewhere ${ }^{32-34}$, and include angiopoietin ${ }^{35}$, CXC chemokine ligand 12 (CXCL12; also known as SDF1) ${ }^{36,37}$, stem cell factor (SCF; also known as steel factor and KIT ligand) ${ }^{38}$ and thrombopoietin ${ }^{39}, 40$. In addition, developmental mediators, such as Notch (reviewed in ${ }^{41}$ ) and Wnt (reviewed in ${ }^{42}$ ) are important for HSC maintenance. Other membrane-bound receptors, such as integrins ${ }^{43}$ and cadherins ${ }^{44}$, also may contribute. Many of these cytokines and developmental regulators are produced by niche cells and by haematopoietic cells.

HSCs require interactions with distinct niches at each stage of ontogeny. Thus, the sequential exposure of HSCs to different extracellular cues may have an important influence on their development and maturation; alternatively, perhaps the common features among 
these niches are exploited by HSCs to support their function in otherwise variant environments. Regardless, the anatomical relocalization of HSCs during development imparts unique challenges for the niches that support them, and suggests that haematopoietic niches may be one of the most dynamic of stem cell supportive niches.

\section{The niche in fetal haematopoiesis}

It has recently become possible to visualize individual HSCs arising from endothelial cells (ECs) of the ventral aspect of the dorsal aorta, using direct in vivo imaging techniques ${ }^{22,45}$. These imaging data provide strong support for the hemogenic endothelium hypothesis ${ }^{46,47}$, which posits that HSCs arise directly from committed ECs. The hemogenic endothelium model is related to, but distinct from, the "hemangioblast" hypothesis, which supposes the existence of a common, bipotent precursor that gives rise to both the vasculature and blood cells during development. Aside from the implications of this work with respect to the origin of HSCs, these imaging studies also argue that the niche for the very earliest HSCs is provided by the very same cells that give rise to those HSCs (Fig. 4).

Newly-formed HSCs emerging from the ventral aspect of the dorsal aorta in the AGM either bud off into the aortic circulation or remain embedded within the endothelium $22,28,45$. The ECs that do not convert to HSCs are capable of supporting HSCs in vitro ${ }^{48}$. One group has undertaken gene expression profiling of the haematopoietic AGM region and performed in situ hybridization to corroborate the results. Although it is difficult to identify cells definitively by in situ analysis of embryo sections, these experiments seem to suggest that p57 (also known as KIP2 and CDKN1C) and insulin-like growth factor 2 (IGF2) are upregulated in ECs underlying emerging $\mathrm{HSCs}^{49}$. It remains unclear, however, precisely how these niche factors influence HSC function. p57 is a cyclin-dependent kinase inhibitor expressed in adult $\mathrm{HSCs}^{50}$ and it is difficult to envision a cell-extrinsic role for this protein in HSC function. By contrast, IGF2 is a secreted growth factor, and culture of HSCs with IGF2 increases the frequency of mixed and erythroid colonies and decreases the frequency of macrophage and granulocyte-macrophage colonies in methylcellulose culture. These data led the authors to conclude that IGF2 signalling promotes the maintenance of primitive multipotent cells and early erythroid precursors at the expense of more mature myeloid precursors ${ }^{49}$. Whatever mechanisms underlie the haematopoietic regulatory function of hemogenic endothelium, these ultimately vanish when distinct somitic endothelial precursors migrate to the ventral aspect of the dorsal aorta and replace the hemogenic endothelium, coincident with the disappearance of haematopoietic potential from the $\mathrm{AGM}^{51}$.

Within half a day of the emergence of HSCs from the ventral aortic endothelium, they can be found in the yolk sac, placenta, and fetal liver. Quantitative analysis suggests that HSCs are independently generated in the yolk sac, placenta and AGM, and cells generated in all of these anatomic sites may colonize the fetal liver ${ }^{52-54}$. The mechanistic basis for HSC emergence in the yolk sac and placenta has not been defined, although by analogy with the AGM, HSCs here might also arise locally from developmentally regulated hemogenic endothelium. Likewise, the factors responsible for the subsequent engraftment of HSCs in the fetal liver are still being elucidated. The chemokine CXCL12, which is expressed by 
stromal cells, and its G-protein coupled receptor CXC chemokine receptor 4 (CXCR4; also known as fusin and CD184), which is expressed on haematopoietic cells and some cancer cells, are clearly important for proper HSC function and migration, including HSC engraftment into fetal liver ${ }^{36,55,56}$. Likewise, the cytokine SCF, which is produced by stromal cells, and its receptor KIT (also known as CD117 and SCFR), which is expressed on pluripotent haematopoietic cells, have long been recognized as critical for HSC function ${ }^{57-59}$. SCF-KIT signalling also appears to amplify the migratory response of fetal HSCs to CXCL12 $2^{57}$. Additional factors suggested to be important for fetal HSC migration and engraftment include a4 integrin ${ }^{43}$, neural cadherin (N-cadherin) and osteopontin ${ }^{60}$, which are membrane-bound adhesion molecules that can activate WNT signalling. Other factors, like the transcription factor pituitary homeobox 2 (PITX2), must be expressed in stromal cells in order to support normal fetal HSC function and maintenance, although the mechanism underlying this effect remains unclear ${ }^{61}$. More recently, BRG1-associated factor 250A (BAF250A; also known as ARID1A), a SWI/SNF (switch/sucrose nonfermentable) family member, has been shown to restrict HSC expansion in the fetal liver in a cell-nonautonomous fashion ${ }^{62}$. BAF250a might accomplish this by altering HSC-stromal cell interactions to reduce $\mathrm{HSC}$ expression of self-renewal and survival factors and enhance expression of genes associated with senescence and apoptosis ${ }^{62}$.

At about day e17.5 in the mouse, fetal haematopoiesis moves to the bone marrow ${ }^{57}$. This relocalization is thought to result from the development, at around day e14.5, of osteoblast and chondrocyte precursor cells that are capable of forming an HSC niche ${ }^{63}$. The signals that are responsible for transferring the bulk of haematopoiesis from the liver to the bone marrow are not entirely understood. However, CXCR4-CXCL12, SCF-KIT, TIE2angiopoietin, integrin and CD44-epithelial cadherin (E-cadherin) adhesion and signalling pathways appear to be important for this process ${ }^{44}$ and for retaining HSCs within the marrow space ${ }^{64}$. In addition, transformation of the liver into a synthetic and digestive organ, which is marked by the differentiation of hepatoblasts into hepatocytes, beginning at about day e15.5 in the mouse ${ }^{65}$, probably results in the replacement of haematopoietic niches with hepatic functional units. This change might drive the relocation of fetal liver HSCs to the bone marrow, where HSC-niche cell relationships enter their adult phase (discussed further below).

Taken together, these recent and historical findings support a co-developmental model of HSC-niche cell interactions throughout ontogeny, wherein haematopoiesis in a new niche occurs concurrently with the maturation of that niche's ability to support haematopoiesis. This model also implies that the waning of haematopoiesis in a particular ontogenic niche may result from the execution of a developmental programme that makes the prior niche inhospitable (Fig. 4), or from the emergence of a new, more 'attractive' niche.

\section{Acellular factors in the adult niche}

In postnatal life, the bone marrow represents the primary reservoir for HSCs and haematopoietic progenitors in both mice and humans. The activity of adult HSCs is carefully regulated by a number of different signals, including many of the cytokines discussed above. Many non-proteinaceous factors, including calcium ions, oxygen tension, and reactive 
oxygen species, also are critical for proper HSC regulation, although such elements have only recently been integrated into the concept of the bone marrow niche. In addition, physical and mechanical inputs, such as shear force and rigidity, are becoming better defined as contributors to niche haematopoiesis. As the role of cytokines in the adult HSC niche has been extensively reviewed by others ${ }^{33}, 34,44,59,66,67$, we focus here on some of the morerecently identified non-cytokine niche components that are implicated in adult haematopoiesis.

\section{Oxygen tension regulates HSC function}

It was suggested several years ago that long-term HSCs (LT-HSCs) reside in a hypoxic niche, with initial studies relying upon Hoechst dye staining as a proxy for perfusion (more intense staining correlates with better perfusion, which presumably correlates with increased oxygenation). These studies did not examine the marrow compartment anatomically; however, subsequent staining with pimonidazole, a chemical marker for hypoxia, confirmed that HSCs were in fact hypoxic ${ }^{68}$. Later studies combined the creative use of Hoechst dye as a hypoxia marker with conventional cell-surface immunophenotyping to evaluate the cellular environment in which HSCs reside. These studies suggested that LT-HSCs are found predominantly in poorly-perfused niches. Moreover, co-staining for mesenchymal stem cells (MSCs), osteoblasts, and vascular ECs revealed that, of these, only osteoblasts are similarly located in poorly-perfused niches; ECs and MSCs (as well as a subset of osteoblasts) were judged to show medium to high staining with Hoechst dye, indicating good perfusion ${ }^{69}$. Unfortunately, these experiments did not couple hypoxia (as measured by the Hoechst dye gradient) to bone marrow anatomy. Thus, these findings provide only indirect evidence that the most quiescent LT-HSCs coexist with osteoblasts in a region far from an oxygenated blood supply.

A recent study in humans, in which bone marrow vasculature was visually compared to anatomically localized HSPCs, demonstrated that most blood vessel fragments in cancellous bone exist within $50 \mu \mathrm{m}$ of the trabecular surface ${ }^{70}$. This study also demonstrated that most HSPCs exist within $200 \mu \mathrm{m}$ of a blood vessel fragment. Because oxygen tension could not be assessed in this study, it is unclear how to reconcile these findings with the Hoechst experiments discussed above. However, unpublished data from the Silberstein laboratory show direct visualization of a hypoxic HSC (using pimonidazole) in close proximity to vascular structures and non-hypoxic B220 ${ }^{+}$B cells (L. Silberstein, personal communication). Such data indicate that although HSCs may indeed be hypoxic, their hypoxic state may be less determined by the niche in which they reside and more by a function of some quality that is intrinsic to the HSCs. Consistent with this notion, recent studies on HSCs themselves support the importance of hypoxia for HSC maintenance ${ }^{71,72}$, and, further, suggest that hypoxic regulation must keep the levels of hypoxia-inducible factor 1a (HIF1a; a transcription factor that is upregulated in mammalian cells growing at low oxygen concentrations) within a certain window. Hypoxic upregulation of HIF1a in HSCs causes a shift away from mitochondrial oxidative phosphorylation and towards glycolysis, which promotes HSC survival in a hypoxic microenvironment ${ }^{73}$. However, deletion of HIF1a leads to HSC proliferation and an eventual exhaustion of repopulating capacity, particularly in conditions of haematopoietic stress ${ }^{72}$; paradoxically, 
overstabilization of HIF1a also leads to HSC loss ${ }^{72}$. Thus, there may exist a narrow window in which the niche is neither too hypoxic nor too hyperoxic and oxygen tension is optimal for HSC maintenance and function. The anatomical localization of this region may be determined by both distance from bone marrow vascular sinuses and HSC-intrinsic signalling. Continued exploitation of newly-developed imaging techniques that permit realtime, in vivo imaging of anatomic and functional niche components ${ }^{74-76}$ should soon enable combined mapping of anatomical and physical niche factors, allowing definitive conclusions about the relationship between anatomic location and HSC hypoxia within the bone marrow microenvironment.

\section{Calcium regulates $\mathrm{HSC}$ function}

Deletion of the calcium ion-sensing receptor in HSCs prevents them from lodging efficiently in the bone marrow and decreases marrow cellularity ${ }^{77}$. Further studies indicate that pharmacologic stimulation of the calcium ion-sensing receptor improves HSC homing to bone marrow and subsequent engraftment ${ }^{78}$, suggesting that calcium ions act as chemoattractants to HSCs. Additionally, inhibition of osteoclasts, the primary liberators of calcium ions in bone, by bisphosphonates decreases HSC numbers and engraftment ${ }^{79}$. However, osteoclasts also can promote HSPC mobilization through effacement of endosteal structures ${ }^{80}$, reflecting a complex and context-dependent role for divalent cations in regulating haematopoiesis.

\section{Shear force and mechanical support regulate HSCs}

It has been shown recently that the circulatory shear stress to which fetal HSCs are subjected in the developing dorsal aorta upregulates nitric-oxide-mediated Runxl transcription ${ }^{5}$. RUNX1 is a well-described transcription factor that regulates the haematopoietic programme ${ }^{81}$. Although the adult bone marrow and dorsal aorta are quite distinct, the bone marrow is exposed to, and continuous with, the circulatory system. It is therefore quite possible that blood flow through the marrow cavity has a role in adult haematopoiesis as well. Additionally, the quality of mechanical support given by the extracellular matrix to many other types of stem cells has been demonstrated to affect their differentiation ${ }^{82-84}$. Thus, in addition to influencing haematopoiesis secondarily, the physical properties of matrix components may directly affect HSC function.

\section{Cellular factors in the adult niche}

The main function of the bone marrow is to provide new blood cells, as needed, throughout life. The bone marrow is highly complex, and conventional representations of bone marrow haematopoiesis often reference an "endosteal niche," which is populated by osteoblasts, and a "vascular niche," which is an anatomically distinct perivascular space. However, this conception is almost certainly an over-simplification, however. Recent advances have refined our understanding of how HSCs interact with niche cells, of which cell types have niche functions and of how acellular aspects of the microenvironment affect haematopoiesis. Further evidence indicates that a single HSC can receive input simultaneously from multiple, distinct types of niche cells and that HSCs may move among these niches quite readily, data that potentially collapses models based on anatomically separate niches (see the 
discussion below on osteoblasts and other niche cells). In aggregate, these studies suggest a new model of marrow haematopoiesis, in which one may visualize the entire bone marrow compartment as a niche, with discrete areas and cellular elements serving distinct functions at different stages of haematopoietic development and differentiation. In this section, we review recent advances in understanding the specific cell types that comprise the bone marrow niche, and how these cells interact with HSCs.

\section{Osteoblasts: canonical niche cells}

Bone-forming osteoblasts interact with HSCs at the interface between the bone and the marrow space, in what has been termed the endosteal niche. The osteoblast is arguably the best characterized of all HSC niche cells. Genetic experiments that increase osteoblast numbers result in increased HSC numbers ${ }^{14}$, and osteoblast ablation ultimately results in loss of $\mathrm{HSCs}^{85,86}$. Although osteoblasts certainly can act as positive regulators of HSC function, the mechanisms underlying that regulation are not entirely clear. Osteoblasts secrete cytokines such as granulocyte colony-stimulating factor (G-CSF), granulocytemacrophage CSF (GM-CSF), and interleukin-6 (IL-6) ${ }^{87}$, which support HSC survival and differentiation. Osteoblasts also express factors that regulate HSC numbers, including angiopoietin, thrombopoietin, WNT, Notch, N-cadherin, and osteopontin ${ }^{40,87-95}$, although it is still unknown how these diverse signals are integrated into a central program. Interestingly, experiments in which micro RNA (miRNA) processing was impaired specifically in osteoblast precursors, through cell-specific deletion of the essential miRNA processing enzyme Dicer, resulted in perturbed haematopoiesis and the onset of a myelodysplasia-like phenomenon ${ }^{96}$. In contrast, Dicer disruption in mature osteoblasts yielded a bone phenotype but no overt changes in haematopoiesis, suggesting stage-specific interactions between this niche cell lineage and $\mathrm{HSCs}^{96}$.

Co-culture experiments further demonstrate the ability of osteoblastic cells to support and maintain HSC growth and function ${ }^{87,97,98}$, confirming functionally their role as HSC niche cells. Two groups recently showed that culture of HSCs with endosteal cells, isolated on the basis of various cell surface markers, is sufficient to maintain long-term reconstituting capacity (that is, the ability of HSCs to reconstitute fully all blood lineages for the life of the organism $)^{97,98}$. Also, these groups demonstrated that the endosteal population is heterogeneous, capable of differentiating in vitro into osteoblasts, adipocytes and chondrocytes, and that these subtypes have a differential ability to support HSC function. The chondrogenic population was the least effective at supporting HSCs and the osteoblastic population was the most effective. The superior function of osteoid cells in these assays may reflect their documented ability to produce multiple signalling molecules that are important in niche-HSC interaction, including Notch and CXCR4 ${ }^{14,41,99-101}$.

The relevance of the in vitro studies described above to the physiological regulation of HSCs has been corroborated recently by in vivo imaging studies, which permit real time, direct, in vivo observation of HSCs interacting with niche cells, and indicate a close physical proximity of HSCs to osteolineage cells ${ }^{76}$. Likewise, studies using advanced confocal techniques to achieve fine-resolution three-dimensional mapping of the endosteal niche ${ }^{74}$ document a close association between newly-engrafted LT-HSCs and the endosteum, 
whereas more mature haematopoietic progenitor cells do not associate as closely with osteoblasts $75,76,102,103$. Yet, in contrast to previous models, which considered the osteoblastic niche to be anatomically distinct from other niches (see below), imaging data from the Scadden ${ }^{76}$ and Silberstein groups (L. Silberstein, personal communication) demonstrate that, although LT-HSCs preferentially lodge close to the endosteum after transplantation, this location typically is proximate to perivascular cells as well, both in the calvarium and the long bones. Thus, it is possible for a single HSC to inhabit simultaneously what had previously been considered to be two discrete haematopoietic niches. Of course, a significant caveat to these imaging studies is that they rely on the transplantation of marked (usually with green fluorescent protein (GFP) HSCs, and such transplantation models may not reflect the true physiology of endogenous HSCs. It also is notable that technical limitations prohibited the concomitant cell-surface staining of visualized HSCs, limiting the investigators' ability to place these cells in a developmental hierarchy with high resolution. Nonetheless, these provocative findings suggest a less anatomically rigid concept of the HSC niche than that currently considered to operate in solid tissue systems.

\section{Various cell types make up the vascular niche}

In addition to osteoblasts, HSCs in the adult bone marrow associate with vascular structures within the marrow cavity. As these structures represent the gateway through which blood cells, including $\mathrm{HSCs}^{16}$, must pass when transiting into or out of the bloodstream, they are clearly candidates for transducing migration, engraftment, and differentiation signals to HSCs. Proximity to the vasculature might also facilitate the sensing of systemic signals by medullary HSCs, which would allow coordination of blood-forming activity in haematopoietic tissues that are spread throughout the body.

Several cell types within the perivascular space, including perivascular MSCs, CXCL12abundant reticular (CAR) cells and neural cells, have been reported to act independently to regulate HSC function. Because most of these perivascular cells have been identified on the basis of non-overlapping or partially-overlapping sets of markers, there is some question as to how distinct these cells really are. It is possible, and even likely, that some of these reported marker systems identify overlapping populations of cells, or that they mark cells at multiple, discrete stages of differentiation within the same lineage.

An elegant set of experiments ${ }^{104}$ recently implicated a population of perivascular nestinexpressing $\left(\mathrm{NES}^{+}\right) \mathrm{MSCs}$ in the regulation of HSC function. Ablation of these $\mathrm{NES}^{+}$cells using an inducible system reduced the number of LT-HSCs in the bone marrow by $50 \%$ between 6 and 14 days after ablation. $\mathrm{NES}^{+}$cells express high levels of CXCL12, which is known to regulate HSC migration ${ }^{105}, 106$, and they are closely associated with sympathetic nerve fibres, which are themselves able to regulate cytokine-induced mobilization of HSCs from the bone marrow ${ }^{107}$. NES $^{+}$MSCs can be differentiated into adipocytes, osteoblasts and chondrocytes, and their HSC regulatory function is modified by sympathectomy or by treatment with G-CSF (which downregulates their ability to express CXCL12, SCF, angiopoietin, IL7, and vascular cell adhesion molecule 1 (VCAM1)). Together, these findings strongly suggest that niche-dependent regulation of HSCs occurs coincidently with niche cell differentiation, as has previously been demonstrated in the interactions of 
developing B cells with osteoblasts 108,109 . Thus, as stromal cells migrate, differentiate and undergo changes in gene expression in response to developmental or physiological cues, the impact that they have on haematopoiesis is also likely to change.

A series of investigations ${ }^{110}$ paralleling the studies on $\mathrm{NES}^{+}$cells has focused on the previously-identified population of CAR cells. These CAR cells were ablated from mice using an inducible system in which a transgene encoding the diphtheria toxin receptor fused to GFP was inserted into the CXCL12 locus. Treatment of these mice with diphtheria toxin allowed the specific deletion of CXCL12-expressing cells and, although the mice died from liver failure 5 days after toxin administration, they demonstrated a severe reduction in CAR cells before death (at 2-3 days after injection). This loss of CAR cells coincided with a 50\% reduction in LT-HSC number ${ }^{110}$. In addition, LT-HSCs in CAR cell-depleted mice were smaller and less-actively cycling, suggesting that the LT-HSCs that remained in these animals were more quiescent than in control mice. Multipotent progenitor (MPP) cell numbers appeared normal in these mice, as they did when CXCR4 was ablated in adult mice by the same group ${ }^{37}$. However, CAR cell-depleted animals showed significant reductions in the number of megakaryocyte-erythroid progenitors (MEPs), granulocyte-monocyte precursors (GMPs), and common lymphoid progentiors (CLPs) — cell types that are derived from MPPs (Fig. 1.). CAR cells differentiate, in vitro, into adipocytes and osteoblasts, and treatment with the myeloablative agent 5-fluorouracil induced CAR cells to preferentially adopt an adipocyte cell fate in vivo. Thus, like the $\mathrm{NES}^{+}$cells discussed above, CAR cells exhibit MSC characteristics, although the degree of overlap between CAR cells and the $\mathrm{NES}^{+}$cells is not yet known. One significant difference between the two cell types is that CAR cells, although predominantly perivascular, are also located at the endosteal surface, whereas $\mathrm{NES}^{+}$cells are reported to be exclusively perivascular ${ }^{104}$. Related to both of these putative niche cell populations, a recent report described the isolation of bone-lining cells that support HSCs and can differentiate in vitro into both adipocytes and osteoblasts, although these cells have poor chondrogenic potential ${ }^{98}$. The lineal relationship between these three sets of putative niche cells (perivascular tripotential $\mathrm{NES}^{+}$cells, perivascular bipotential or tripotential CAR cells and endosteal bipotential precursors, see Fig. 5) remains to be elucidated.

Accumulating evidence supports the critical role of marrow innervation in moderating the function of HSCs and their interaction with other niche cells. HSC activity seems to be regulated by both the sympathetic and parasympathetic systems. This regulation clearly can occur indirectly, as both sympathetic receptor blockade and sympathectomy affect stromal cell numbers and function ${ }^{107}$. However, human HSPCs also express and respond to signalling through dopaminergic and adrenergic receptors ${ }^{111,112}$, indicating that direct neural inputs could regulate HSC activity.

Early studies employing static imaging of immunofluorescently marked $\mathrm{HSCs}^{13}$ had suggested that ECs might regulate HSCs in the marrow and the spleen, based on their close anatomical proximity. This hypothesis has gained further support from more-recent studies that identify true vascular ECs as important HSC niche components ${ }^{113}{ }^{114}$. ECs can be distinguished from other bone marrow perivascular cells by their lack of surface cell antigen 1 (SCA1) expression. Marrow ECs also express the vascular markers vascular endothelial 
growth factor receptor (VEGFR; subtypes 2 and 3), platelet EC adhesion molecule (PECAM1; also known as CD31), and vascular endothelial cadherin (VE-cadherin; also known as CD144). Initial characterization of ECs used antibody-mediated in vivo disruption of VEGFR signalling to target ECs in recipient mice, which resulted in poor engraftment of transplanted donor bone marrow cells ${ }^{115}$. However, this result could theoretically arise from indirect inhibition of vascular sinusoid-associated non-EC cells, and so direct assessment of the ability of ECs to support haematopoiesis was needed to verify this finding. Unfortunately, sinusoidal ECs are impossible to culture from bone marrow without manipulation, and subsequent in vitro studies have had to rely on semi-immortalized transfected human umbilical vein ECs (HUVECs). HUVECs transfected with the adenovirus E4 gene E4ORF1, which constitutively activates AKT $1^{114}$, secrete factors that are important to non-angiogenic tissue growth, such as IGF-binding protein 2 (IGFBP2), bone morphogenic protein 4 (BMP4) and fibroblast growth factor 2 (FGF2). In addition, these transfected ECs signal through the Notch and angiopoietin pathways to support and maintain LT-HSCs. By contrast, ECs transfected with a constitutively-active $R A F$ construct, which activates the mitogen-activated protein kinase (MAPK) pathway, downregulate stem cell maintenance factors and upregulate factors that promote HSPC expansion and differentiation, such as IL-6, angiogenin 2 and Notch ligands. These data strongly suggest that ECs are competent to fulfil haematopoietic niche activities; however, direct functional validation of this conclusion in vivo is still needed.

In light of the identification of many distinct perivascular stromal cells capable of affecting haematopoiesis, and the new knowledge that HSCs are frequently positioned in close proximity to both osteoblasts and vascular structures, a more holistic model of the niche is required in which HSCs may simultaneously interact with, and respond to, multiple different niche cell inputs. Further studies that define precisely how each of the many perivascular cell types described above interacts with HSCs, with each other, and with other elements of the marrow microenvironment will help to clarify the complicated and tightly regulated developmental program that controls haematopoiesis.

\section{Negative regulation of HSCs by adipocytes}

In addition to the osteolineage and perivascular cells discussed above, the bone marrow contains lipid-storing adipocytes, the abundance of which increases with age and obesity, and after haematotoxic injuries, such as chemotherapy or irradiation ${ }^{116-120}$. Only recently has it become clear that, far from simply filling space in the marrow, adipocytes actively and directly regulate HSC function, apparently in a negative manner. This observation stems most convincingly from work in which HSCs isolated from adipocyte-rich tail vertebrae showed reduced activity in transplantation assays, as compared to HSCs isolated from adipocyte-poor thoracic vertebrae ${ }^{121}$. Additionally, inhibition of adipogenesis by genetic or pharmacologic interventions resulted in improved HSC function. Recognizing that reduced adipogenesis is accompanied by increased osteogenesis in their systems, the researchers also attempted to study the adipocytic interaction in isolation, by culturing HSCs with adipocytedifferentiated OP9 stromal cells. Such cultures resulted in poorer HSC function.

Complementing these findings, studies of obese leptin-deficient mice (ob/ob mice) $)^{122}$ and leptin receptor-deficient $(d b / d b \text { mice })^{123}$ indicate that these animals exhibit impaired 
haematopoiesis, with relative bone marrow hypocellularity and myeloid skewing. Intriguingly, at least some of these defects can be ameliorated when $d b / d b$ mice are joined to wild-type partners in parabiosis for four weeks, thereby exposing them to a non-obese systemic circulation ${ }^{123}$. These data may indicate the presence of systemic factors in nonobese mice that can overcome HSC suppression by the obese niche, even though hyperglycaemia and elevated insulin levels in $d b / d b$ partners were not lowered by parabiosis ${ }^{123}$. Alternatively, because these analyses focused on peripheral blood and not bone marrow, these results could reflect effects on more mature cells, such as the transiting of circulating precursor cells through the non-obese circulation.

Finally, studies in which both osteoblasts and adipocyte-containing bone marrow stromal cells were isolated demonstrate a significant negative influence of adipocytic cells on the ex vivo proliferation and haematopoietic colony-forming ability of HSPCs ${ }^{97}$. This suppression could not be overcome in mixed osteoblast-stromal cell cultures and may relate to the elevated expression of neuropilin 1 (NRP1), a non-classic VEGF and semaphorin receptor that is important in both angiogenesis and neuronal cell guidance ${ }^{97}$. NRP1 has been shown in cell culture to inhibit granulopoiesis and promote myelopoiesis from human $\mathrm{CD} 34^{+}$cells via inhibition of G-CSF production ${ }^{124}$, and NRP1 expression was elevated in the inhibitory stromal cell fraction, suggesting that its overproduction by adipocytic stromal cells may contribute to their dominant inhibition of haematopoietic activity.

Taken together, the studies discussed above strongly suggest that adipocytes mediate a direct, inhibitory influence on HSC function. However, the fact that adipocytes and osteoblasts co-exist in dynamic opposition, with adipocyte numbers increasing when osteoblast numbers decrease (and vice versa), and that adipocytes and osteoblasts sometimes derive from the same precursor cell, complicates efforts to isolate the specific contribution (or contributions) of each cell type. In in vivo studies, effects attributed to one cell type may be partially influenced or overshadowed by the absence of an opposing effect of the other cell type. New systems are needed to enable the examination or manipulation of each cell type in isolation in order to distinguish their direct effects on HSCs. In any event, existing data provides an emerging picture of the HSC niche, suggesting that it must invoke complex interactions between many different stromal cell types to explain the dynamic regulation of marrow haematopoiesis.

\section{The niche in dysregulated haematopoiesis}

Although most haematopoietic malignancies are likely to arise from mutations that inappropriately activate haematopoietic cell proliferation and survival pathways, recent data demonstrate that haematopoiesis can also be dysregulated by alterations in the niche, with defects in HSCs themselves arising secondarily. The most compelling recent example comes from work in which miRNA processing was disrupted in osteoblast precursors and mice developed myelodysplasia, which in rare cases progressed to myeloid leukaemia by 3 weeks of age ${ }^{96}$. Notably, HSCs transplanted from these mice into wild-type recipients did not transfer myelodysplasia, indicating that the HSCs were not intrinsically competent to produce pathologic changes. Similarly, APC ${ }^{\text {min }}$ (adenomatous polyposis coli, multiple intestinal neoplasia) mice, which are heterozygous for a truncated, nonfunctional allele of 
the tumour suppressor and negative regulator of canonical WNT signalling APC, develop myelodysplasia as they age, and this phenotype is not rescued by transplanting wild-type CD45.1 bone marrow ${ }^{125}$. Of note, these transplantation experiments used sublethallyirradiated recipients, leaving open the possibility that the continued formation of blood cells from residual $\mathrm{APC}^{\mathrm{min}} \mathrm{HSPCs}$ contributed to the development of myelodysplasia in these animals. Nonetheless, these studies add to a growing body of evidence indicating that malignancy and premalignancy can arise from microenvironmental defects ${ }^{126,127}$, or from cooperation between haematopoietic and niche cells. This appears to be the case for the myeloproliferation that develops in mice deficient in the retinoblastoma $(\mathrm{RB})$ protein; haematopoietic dysfunction in this model requires deletion of $R b$ in both niche cells and myeloid cells ${ }^{127}$.

Other suggestions of microenvironmentally-driven haematopoietic dysfunction come from the literature on ageing. Ageing is accompanied by well-described haematopoietic changes, including an accumulation of phenotypic HSCs with diminished repopulating capacity, as well as a propensity towards myelopoiesis instead of lymphopoiesis ${ }^{128-133}$. Although HSCintrinsic changes undoubtedly contribute to these age-associated phenotypes ${ }^{131}$, changes also occur in the microenvironment over time ${ }^{133}$. For instance, mammalian target of rapamycin (mTOR) signalling is increased in aged HSCs, presumably as a result of microenvironmental cues ${ }^{134}$. Heightened mTOR signalling in aged HSCs suppresses their engraftment function and appears to contributed to age-dependent deficits in immune function ${ }^{134}$. Additionally, recent proteomic analysis of bone marrow stromal cells in culture demonstrates that older stromal cells produce more hydrogen peroxide than younger cells ${ }^{135}$, which could lead to increased production of oxygen free radicals. This potentially more-toxic environment may have deleterious effects on HSC function.

Toxic insults that cause DNA damage, such as ionizing radiation, might also adversely affect haematopoiesis, in part owing to the preferential use of particular DNA damage response mechanisms in HSCs. Quiescent HSCs preferentially employ non-homologous end joining in response to radiation-induced DNA damage, and this repair pathway is prone to introducing base deletions and additions ${ }^{136,137}$. Irradiation also has profound effects on niche cells themselves, including osteoblasts and adipocytes. Although the marrow space becomes infiltrated by adipocytes soon after irradiation ${ }^{119,138}$, the first response to a radiation insult is a transient and reversible proliferation of osteoblasts, which peaks at $48 \mathrm{~h}$ post-irradiation and disappears by 10 days post-transplant ${ }^{139}$. Interestingly, emerging data indicates that irradiation is more disruptive of bone marrow architecture than chemotherapy (J.R. Harris, J.P. Chute and T. Reya, personal communication). The administration of cyclophosphamide to mice at conventional doses resulted in severe myelotoxicity but significantly less damage to the bone marrow architecture in comparison to radiation, which caused extensive destruction of both haematopoietic cells and bone marrow stromal cells, as well as delayed haematologic recovery. These findings suggest that systemic toxins are likely to have very distinct deleterious effects on HSCs and stromal cells.

Finally, obesity in humans has been correlated both with changes in the bone marrow microenvironment ${ }^{120}$ and with an increased incidence of haematologic malignancy ${ }^{140}$. Although the mechanisms underlying these findings remain to be elucidated, it is probable 
that they arise from a combination of systemic and cell-mediated interactions. Interestingly, obese diabetic BBZDR/Wor rats exhibit increased numbers of marrow adipocytes and impaired innervation of bone marrow stromal elements relative to controls, suggesting a link between obesity and disruption of the multicomponent HSC niche described above ${ }^{141}$. Whether this disruption is a function of specific adipocyte-mediated local signals (for example, NRP1), systemic inflammatory signals (for example, transforming growth factor$\beta$ ), or of a niche interaction that is not yet described, is a topic of great interest for future study.

\section{A look ahead: the HSC niche in therapy}

Inadequate, impaired, or dysregulated haematopoiesis accounts for a substantial fraction of morbidity and mortality in today's society and, until recently, most therapies have focused somewhat selectively on fixing blood cells and their progenitors directly. The new findings discussed in this Review indicate that haematopoiesis is likely to be driven as much by microenvironmental cues from the niche as by cell-intrinsic ones. There remain many open questions concerning the regulation of haematopoiesis by niche factors. Chief among them is if and how inputs from different niche components are spatially and temporally segregated from the perspective of the HSC. How HSCs influence many of the niche components discussed above is also unknown. Additionally, it is still unclear whether specific niche inputs vary in different bone marrow locations (for example, calvarial niches as compared with femoral diaphyseal niches and femoral metaphyseal niches), and how niche inputs in a given location change over time.

Despite the many unanswered questions, our new understanding of the importance of the microenvironment in haematopoiesis allows the development of novel therapeutic strategies that target the niche in order to correct haematopoietic dysfunction. These studies further highlight the limitations of therapies that are aimed only at HSCs. Already, researchers are developing innovative methods of therapeutically targeting the niche: by creating ectopic niches using biomimetic structures ${ }^{142,143}$ or mesenchymal stem cells ${ }^{144}$; by creating artificial niche-like environments ex vivo ${ }^{145}, 146$; and by making use of agents known to modulate haematopoiesis in vivo via the niche ${ }^{147,148}$. Indeed, there are already many open clinical trials that seek to manipulate the niche in vivo or to reconstitute a synthetic niche in vitro, in the hope of effecting specific therapeutic changes within HSCs. In 2006, a multicenter Phase II clinical trial of parathyroid hormone (PTH; which stimulates bone formation and has been shown to increase HSC numbers endogenously and in transplant models ${ }^{14}$ ) administration to patients who received double-unit umbilical cord blood (UCB) transplantation was undertaken (ClinicalTrials.gov identifier: NCT00579722), although that trial was unfortunately halted because it reached an early stopping rule probably unrelated to the PTH therapy. Other trials using prostagalndin E2 (ClinicalTrials.gov identifier: NCT00890500) and Notch ligands (ClinicalTrials.gov identifier: NCT01175785) administered ex vivo to expand UCB stem cells before transplant are actively recruiting, as is a study in which UCB cells are co-cultured on MSCs (ClinicalTrials.gov identifier: NCT00498316). A trial using StemRegenin $1^{71}$ to expand UCB grafts will open soon, and medications like AMD3100 (ClinicalTrials.gov identifier: NCT00075335) and hepatocytes growth factor ${ }^{149}$ are poised to join G-CSF and GM-CSF in the small but potent arsenal of 
HSPC mobilizing agents. As these therapies move into clinical practice, however, it will be increasingly important to understand not only how they affect haematopoiesis but also how they affect the haematopoietic niche. Understanding the composition of the niche and the complex interactions between niche elements and HSCs has never been more critical or timely. Only through a deeper understanding of this intricate support system can we truly learn how to engineer haematopoiesis to combat haematopoietic disease.

\section{Acknowledgments}

We thank L. Silberstein and T. Reya for provision of unpublished data and C. Dall'Osso, A. Hartigan and T. Nageswara Rao for helpful comments on the manuscript. This work was funded, in part, by grants from the US National Institutes of Health (NIH) (HL088582 and HL100402 to A.J.W.) and the Keck Foundation. L.D.W. is supported by an NIH T32 Training Grant (T32CA136432). Content is solely the responsibility of the authors and does not necessarily represent the official views of the NIH or other funding agencies.

\section{Glossary}

\begin{abstract}
Aorta-gonadmesonephros (AGM)
\end{abstract}

Myelodysplasia

Extramedullary

\author{
Haemogenic \\ endothelium
}

Haemangioblast

Cancellous bone (also known as trabecular bone)

Homing a region of embryonic mesoderm that develops from para-aortic splanchnopleura during embryogenesis and gives rise to definitive HSCs

general term for haematologic defects involving deficiencies in the myeloid blood lineages, which in fact manifest dysfunction in multiple blood lineages. Myelodysplasias are sometimes referred to as 'preleukaemias' because they can transform over time

'outside the marrow.' Used to describe blood formation occurring in anatomical locations distinct from the bone marrow. In adults, extramedullary hematopoiesis often signifies hematopoietic stress

a layer of committed endothelial cells that have the capacity to differentiate into blood cells, losing endothelial characteristics and adopting hematopoietic features

an undifferentiated precursor cell formed during development that has the potential to give rise (at the single cell level) to blood cells and endothelial cells, but not to other cell lineages

the spongy osseous tissue located at the ends of long bones and within vertebral bodies. It contains haematopoietic (red) marrow but, unlike the medullary cavity of the long bones, also contains trabeculae (tiny osseous beams that traverse the cancellous bone, creating an anatomical and functional structure through which blood and bone marrow elements transit)

the process whereby haematopoietic stem cells (HSCs) find their way from the circulation to the haematopoietic 'niche'. It is distinct from lodgement, which is the ability of HSCs to enter into the niche and stay there, as well as from engraftment, which is the 


\section{Endosteal \\ structures}

Osteoid cells

osteocytes

Long-term HSCs

CXCL12-abundant reticular cells

(CAR cells)

Vascular sinusoid

Parabiosis

Non-homologous

end joining (NHEJ) ability of HSCs to respond to appropriate maintenance and differentiation signals when lodged

elements of the endosteum, which is a connective-tissue membrane the lines the inner surface of the medullary (marrow) cavity of the bone. Many researchers also refer to the endosteum as the inner surfaces of the bone (that is, the location of osteoblasts; see the glossary entry for osteoid cells)

cells of the bone lineage

osteoblasts, and their precursors. Osteoclasts are not osteoid cells, as they are haematopoietic in origin. Anatomically, osteoid is the unmineralized immature bone matrix laid down by osteoblasts and containing osteocytes

long-term haematopoietic stem cells; LT-HSCs. Cells that are capable of nearly indefinite self-renewal and differentiation into the mature cells of all blood lineages (as assayed by transplantation). These are the bona fide stem cells of haematopoiesis. They are operationally distinct from short-term HSCs, which are capable of only limited self-renewal (but competent to differentiate into the mature cells of all blood lineages) and therefore cannot reconstitute hematopoiesis for the life of an organism

cells that were originally identified on the basis of their high expression of the CXC chemokine ligand 12 (CXCL12). CAR cells can be perivascular or endosteal in location

a fenestrated capillary-sized blood vessel. Sinusoids are quite porous, permitting the free passage of many blood components

a surgical procedure whereby the circulatory systems of two animals are joined such that there is free flow of blood between them

a double-strand DNA break repair mechanism that does not make use of a homologous DNA template and is therefore more errorprone than homologous recombination

\section{References}

1. Schofield R. The relationship between the spleen colony-forming cell and the haemopoietic stem cell. Blood Cells. 1978; 4:7-25. This seminal paper was first to apply the concept of the niche to stem cell biology, postulating that loss of HSC association with the niche would result in differentiation. [PubMed: 747780]

2. Eliasson P, Jonsson J. The hematopoietic stem cell niche: Low in oxygen but a nice place to be. J Cell Physiol. 2009; 222:17-22. [PubMed: 19725055] 
3. Eliasson P, et al. Hypoxia mediates low cell-cycle activity and increases the proportion of longterm-reconstituting hematopoietic stem cells during in vitro culture. Experimental Hematology. 2010; 38:301-310.e2. [PubMed: 20138114]

4. Kulkeaw K, Ishitani T, Kanemaru T, Fucharoen S, Sugiyama D. Cold exposure down-regulates zebrafish hematopoiesis. Biochemical and Biophysical Research Communications. 2010; 394:859864. [PubMed: 20100463]

5. Adamo L, et al. Biomechanical forces promote embryonic haematopoiesis. Nature. 2009; 459:11315. Demonstrates that shear stress increases Runxl expression and colony-forming potential in embryonic stem cells differentiated in vitro into HSCs, and in hematopoietic precursors in the AGM region of mouse embryos. [PubMed: 19440194]

6. Guzmán A, et al. Formation of micronucleated erythrocytes in mouse bone-marrow under conditions of hypothermia is not associated with stimulation of erythropoiesis. Mutat Res. 2008; 656:8-13. [PubMed: 18718553]

7. Proulx C, Dupuis N, St-Amour I, Boyer L, Lemieux R. Increased megakaryopoiesis in cultures of CD34-enriched cord blood cells maintained at 39 degrees C. Biotechnol Bioeng. 2004; 88:675-80. [PubMed: 15532059]

8. Xie T, Spradling AC. decapentaplegic is essential for the maintenance and division of germline stem cells in the Drosophila ovary. Cell. 1998; 94:251-60. [PubMed: 9695953]

9. Xie T, Spradling AC. A niche maintaining germ line stem cells in the Drosophila ovary. Science. 2000; 290:328-30. [PubMed: 11030649]

10. Kimble JE, White JG. On the control of germ cell development in Caenorhabditis elegans. Dev Biol. 1981; 81:208-19. [PubMed: 7202837]

11. Zhang J, et al. Identification of the haematopoietic stem cell niche and control of the niche size. Nature. 2003; 425:836-41. [PubMed: 14574412]

12. Tumbar T, et al. Defining the epithelial stem cell niche in skin. Science. 2004; 303:359-63. [PubMed: 14671312]

13. Kiel MJ, et al. SLAM family receptors distinguish hematopoietic stem and progenitor cells and reveal endothelial niches for stem cells. Cell. 2005; 121:1109-21. [PubMed: 15989959]

14. Calvi LM, et al. Osteoblastic cells regulate the haematopoietic stem cell niche. Nature. 2003; 425:841-6. [PubMed: 14574413]

15. Gordon MD, Vetto J, Meshul CK, Schmidt WA. FNA of extraskeletal myxoid chondrosarcoma: cytomorphologic, EM, and X-ray microanalysis features. Diagn Cytopathol. 1994; 10:352-6. [PubMed: 7924809]

16. Wright DE, Wagers AJ, Gulati AP, Johnson FL, Weissman IL. Physiological migration of hematopoietic stem and progenitor cells. Science. 2001; 294:1933-6. [PubMed: 11729320]

17. Dzierzak E, speck N. Of lineage and legacy: the development of mammalian hematopoietic stem cells. Nature Immunology. 2007; 9:129-136. [PubMed: 18204427]

18. Badillo AT, Flake AW. The regulatory role of stromal microenvironments in fetal hematopoietic ontogeny. Stem Cell Rev. 2006; 2:241-6. [PubMed: 17625260]

19. Ottersbach K, Smith A, Wood A, Gottgens B. Ontogeny of haematopoiesis: recent advances and open questions. British Journal of Haematology. 2010; 148:343-355. [PubMed: 19863543]

20. Weissman, I.; Papaioannou, V.; Gardner, R. Fetal Hematopoietic Origins of the Adult Hematolymphoid System. Differentiation of Normal and Neoplastic Hematopoietic Cells (Cold Spring Harbor Conferences on Cell Proliferation 5); 1978.

21. Samokhvalov IM, Samokhvalova NI, Nishikawa SI. Cell tracing shows the contribution of the yolk sac to adult haematopoiesis. Nature. 2007; 446:1056-61. [PubMed: 17377529]

22. Boisset JC, et al. In vivo imaging of haematopoietic cells emerging from the mouse aortic endothelium. Nature. 2010; 464:116-120. [PubMed: 20154729]

23. Eilken HM, Nishikawa SI, Schroeder T. Continuous single-cell imaging of blood generation from haemogenic endothelium. Nature. 2009; 457:896-900. [PubMed: 19212410]

24. Cumano A, Dieterlen-Lievre F, Godin I. Lymphoid potential, probed before circulation in mouse, is restricted to caudal intraembryonic splanchnopleura. Cell. 1996; 86:907-16. [PubMed: 8808626] 
25. Kalev-Zylinska ML, et al. Runx3 is required for hematopoietic development in zebrafish. Dev Dyn. 2003; 228:323-36. [PubMed: 14579373]

26. Kalev-Zylinska ML, et al. Runx1 is required for zebrafish blood and vessel development and expression of a human RUNX1-CBF2T1 transgene advances a model for studies of leukemogenesis. Development. 2002; 129:2015-30. [PubMed: 11934867]

27. Burns $\mathrm{CE}$, et al. Isolation and characterization of runxa and runxb, zebrafish members of the runt family of transcriptional regulators. Experimental Hematology. 2002; 30:1381-9. [PubMed: 12482499]

28. Kissa K, Herbomel P. Blood stem cells emerge from aortic endothelium by a novel type of cell transition. Nature. 2010; 464:112-115. [PubMed: 20154732]

29. Rosselló CA, Torres M. Gene transfer by electroporation into hemogenic endothelium in the avian embryo. Dev Dyn. 2010; 239:1748-54. [PubMed: 20503370]

30. Bigas A, Robert-Moreno A, Espinosa L. The Notch pathway in the developing hematopoietic system. Int J Dev Biol. 2010; 54:1175-88. [PubMed: 20711994]

31. Wolber FM, et al. Roles of spleen and liver in development of the murine hematopoietic system. Exp Hematol. 2002; 30:1010-9. [PubMed: 12225792]

32. Yin T, Li L. The stem cell niches in bone. J Clin Invest. 2006; 116:1195-201. [PubMed: 16670760]

33. Askmyr M, Sims NA, Martin TJ, Purton LE. What is the true nature of the osteoblastic hematopoietic stem cell niche? Trends in endocrinology and metabolism: TEM. 2009; 20:303309. [PubMed: 19595609]

34. Kiel MJ, Morrison SJ. Uncertainty in the niches that maintain haematopoietic stem cells. Nature Reviews Immunology. 2008; 8:290-301.

35. Arai F, et al. Tie2/angiopoietin-1 signaling regulates hematopoietic stem cell quiescence in the bone marrow niche. Cell. 2004; 118:149-61. [PubMed: 15260986]

36. Nagasawa T, et al. Defects of B-cell lymphopoiesis and bone-marrow myelopoiesis in mice lacking the CXC chemokine PBSF/SDF-1. Nature. 1996; 382:635-8. [PubMed: 8757135]

37. Sugiyama T, Kohara H, Noda M, Nagasawa T. Maintenance of the hematopoietic stem cell pool by CXCL12-CXCR4 chemokine signaling in bone marrow stromal cell niches. Immunity. 2006; 25:977-88. [PubMed: 17174120]

38. Barker JE. S1/Sld hematopoietic progenitors are deficient in situ. Experimental Hematology. 1994; 22:174-7. [PubMed: 7507859]

39. Yoshihara H, et al. Thrombopoietin/MPL signaling regulates hematopoietic stem cell quiescence and interaction with the osteoblastic niche. Cell Stem Cell. 2007; 1:685-97. [PubMed: 18371409]

40. Qian $\mathrm{H}$, et al. Critical role of thrombopoietin in maintaining adult quiescent hematopoietic stem cells. Cell Stem Cell. 2007; 1:671-84. [PubMed: 18371408]

41. Weber JM, Calvi LM. Notch signaling and the bone marrow hematopoietic stem cell niche. Bone. 2010; 46:281-5. [PubMed: 19679213]

42. Luis TC, Staal FJ. WNT proteins: environmental factors regulating HSC fate in the niche. Ann N Y Acad Sci. 2009; 1176:70-6. [PubMed: 19796234]

43. Qian H, et al. Distinct roles of integrins alpha6 and alpha4 in homing of fetal liver hematopoietic stem and progenitor cells. Blood. 2007; 110:2399-407. [PubMed: 17586725]

44. Magnon C, Frenette PS. Hematopoietic stem cell trafficking. StemBook. 2008:1-24.

45. Bertrand JY, et al. Haematopoietic stem cells derive directly from aortic endothelium during development. Nature. 2010; 464:108-11. References 22, 23, 28, and 45 use real-time imaging to demonstrate that HSCs arise from the aortic endothelium in the AGM. References 22 and 23 show this in mice, whereas references 28 and 45 examine zebrafish. [PubMed: 20154733]

46. His W. Lecithoblast und Angioblast der Wirbelthiere. Histogenetische studien. Abhandl MathPhys Ges Wiss. 1900; 26:171-328.

47. Murray PDF. The Development in vitro of the Blood of the Early Chick Embryo. Proceedings of the Royal Society of London. Series B, Containing Papers of a Biological Character. 1932; 111:497-521. 
48. Oostendorp RAJ, et al. Stromal cell lines from mouse aorta-gonads-mesonephros subregions are potent supporters of hematopoietic stem cell activity. Blood. 2002; 99:1183-9. [PubMed: 11830464]

49. Mascarenhas MI, Parker A, Dzierzak E, Ottersbach K. Identification of novel regulators of hematopoietic stem cell development through refinement of stem cell localization and expression profiling. Blood. 2009; 114:4645-4653. [PubMed: 19794138]

50. Yamazaki S, et al. Cytokine signals modulated via lipid rafts mimic niche signals and induce hibernation in hematopoietic stem cells. EMBO J. 2006; 25:3515-23. [PubMed: 16858398]

51. Esner M, et al. Smooth muscle of the dorsal aorta shares a common clonal origin with skeletal muscle of the myotome. Development. 2006; 133:737-49. [PubMed: 16436625]

52. Gekas C, Dieterlen-Lièvre F, Orkin SH, Mikkola HKA. The placenta is a niche for hematopoietic stem cells. Dev Cell. 2005; 8:365-75. [PubMed: 15737932]

53. Ottersbach K, Dzierzak E. The murine placenta contains hematopoietic stem cells within the vascular labyrinth region. Dev Cell. 2005; 8:377-87. [PubMed: 15737933]

54. Kumaravelu P, et al. Quantitative developmental anatomy of definitive haematopoietic stem cells/ long-term repopulating units (HSC/RUs): role of the aorta-gonad-mesonephros (AGM) region and the yolk sac in colonisation of the mouse embryonic liver. Development. 2002; 129:4891-9. [PubMed: 12397098]

55. Ma Q, et al. Impaired B-lymphopoiesis, myelopoiesis, and derailed cerebellar neuron migration in CXCR4- and SDF-1-deficient mice. Proc Natl Acad Sci USA. 1998; 95:9448-53. [PubMed: 9689100]

56. McGrath KE, Koniski AD, Maltby KM, McGann JK, Palis J. Embryonic expression and function of the chemokine SDF-1 and its receptor, CXCR4. Dev Biol. 1999; 213:442-56. [PubMed: 10479460]

57. Christensen JL, Wright DE, Wagers AJ, Weissman IL. Circulation and chemotaxis of fetal hematopoietic stem cells. PLoS Biol. 2004; 2:E75. [PubMed: 15024423]

58. McCulloch EA, Siminovitch L, Till JE, Russell ES, Bernstein SE. The cellular basis of the genetically determined hemopoietic defect in anemic mice of genotype Sl-Sld. Blood. 1965; 26:399-410. [PubMed: 5317869]

59. Broxmeyer HE, et al. The kit receptor and its ligand, steel factor, as regulators of hemopoiesis. Cancer Cells. 1991; 3:480-7. [PubMed: 1726456]

60. Martin MA, Bhatia M. Analysis of the human fetal liver hematopoietic microenvironment. Stem Cells Dev. 2005; 14:493-504. [PubMed: 16305335]

61. Kieusseian A, et al. Expression of Pitx2 in stromal cells is required for normal hematopoiesis. Blood. 2006; 107:492-500. [PubMed: 16195330]

62. Krosl J, et al. A mutant allele of the Swi/Snf member BAF250a determines the pool size of fetal liver hemopoietic stem cell populations. Blood. 2010; 116:1678-1684. [PubMed: 20522713]

63. Chan C, et al. Endochondral ossification is required for haematopoietic stem-cell niche formation. Nature. 2009; 457:490-4. [PubMed: 19078959]

64. Broxmeyer HE, et al. Rapid mobilization of murine and human hematopoietic stem and progenitor cells with AMD3100, a CXCR4 antagonist. J Exp Med. 2005; 201:1307-18. [PubMed: 15837815]

65. Shiojiri N. Development and differentiation of bile ducts in the mammalian liver. Microsc Res Tech. 1997; 39:328-35. [PubMed: 9407543]

66. Ehninger A, Trumpp A. The bone marrow stem cell niche grows up: mesenchymal stem cells and macrophages move in. Journal of Experimental Medicine. 2011; 208:421-8. [PubMed: 21402747]

67. Arai F, et al. Niche regulation of hematopoietic stem cells in the endosteum. Ann N Y Acad Sci. 2009; 1176:36-46. [PubMed: 19796231]

68. Parmar K, Mauch P, Vergilio JA, Sackstein R, Down JD. Distribution of hematopoietic stem cells in the bone marrow according to regional hypoxia. Proceedings of the National Academy of Sciences of the United States of America. 2007; 104:5431-5436. [PubMed: 17374716]

69. Winkler IG, et al. Positioning of bone marrow hematopoietic and stromal cells relative to blood flow in vivo: serially reconstituting hematopoietic stem cells reside in distinct nonperfused niches. Blood. 2010; 116:375-385. Makes the case that HSCs reside in a functionally hypoxic niche, 
because HSCs that do not stain with Hoechst dye (and are therefore poorly-perfused) exhibit superior long-term reconstitution than HSCs that do take up Hoechst dye. [PubMed: 20393133]

70. Bourke V, et al. Spatial gradients of blood vessels and hematopoietic stem and progenitor cells within the marrow cavities of the human skeleton. Blood. 2009; 114:4077-4080. [PubMed: 19749092]

71. Boitano AE, et al. Aryl Hydrocarbon Receptor Antagonists Promote the Expansion of Human Hematopoietic Stem Cells. Science. 2010; 329:1345-1348. Uses a high-throughput chemical screen to identify a small molecule antagonist of the aryl hydrocarbon receptor (AHR) pathway that potently expands engraftable UCB HSCs ex vivo. [PubMed: 20688981]

72. Takubo K, et al. Regulation of the HIF-1 alpha Level Is Essential for Hematopoietic Stem Cells. Stem Cell. 2010; 7:391-402.

73. Simsek T, et al. The Distinct Metabolic Profile of Hematopoietic Stem Cells Reflects Their Location in a Hypoxic Niche. Stem Cell. 2010; 7:380-390.

74. Takaku T, et al. Hematopoiesis in 3 dimensions: human and murine bone marrow architecture visualized by confocal microscopy. Blood. 2010; 116:e41-e55. [PubMed: 20647571]

75. Kohler A, et al. Altered cellular dynamics and endosteal location of aged early hematopoietic progenitor cells revealed by time-lapse intravital imaging in long bones. Blood. 2009; 114:290 298. [PubMed: 19357397]

76. Lo Celso C, et al. Live-animal tracking of individual haematopoietic stem/progenitor cells in their niche. Nature. 2009; 457:92-97. [PubMed: 19052546]

77. Adams GB, et al. Stem cell engraftment at the endosteal niche is specified by the calcium-sensing receptor. Nature. 2006; 439:599-603. [PubMed: 16382241]

78. Lam BS, Cunningham C, Adams GB. Pharmacologic modulation of the calcium-sensing receptor enhances hematopoietic stem cell lodgment in the adult bone marrow. Blood. 2011; 117:11671175. [PubMed: 21076044]

79. Lymperi S, Ersek A, Ferraro F, Dazzi F, Horwood NJ. Inhibition of osteoclast function reduces hematopoietic stem cell numbers in vivo. Blood. 2011; 117:1540-1549. [PubMed: 21131587]

80. Kollet $\mathrm{O}$, et al. Osteoclasts degrade endosteal components and promote mobilization of hematopoietic progenitor cells. Nat Med. 2006; 12:657-64. [PubMed: 16715089]

81. North TE, et al. Runx 1 expression marks long-term repopulating hematopoietic stem cells in the midgestation mouse embryo. Immunity. 2002; 16:661-72. [PubMed: 12049718]

82. Keung AJ, Healy KE, Kumar S, Schaffer DV. Biophysics and dynamics of natural and engineered stem cell microenvironments. Wiley Interdiscip Rev Syst Biol Med. 2010; 2:49-64. [PubMed: 20836010]

83. Engler AJ, Sen S, Sweeney HL, Discher DE. Matrix elasticity directs stem cell lineage specification. Cell. 2006; 126:677-89. [PubMed: 16923388]

84. Gilbert PM, et al. Substrate elasticity regulates skeletal muscle stem cell self-renewal in culture. Science. 2010; 329:1078-81. [PubMed: 20647425]

85. Visnjic D, et al. Conditional ablation of the osteoblast lineage in Col2.3deltatk transgenic mice. Journal of Bone and Mineral Research. 2001; 16:2222-2231. [PubMed: 11760835]

86. Visnjic D, et al. Hematopoiesis is severely altered in mice with an induced osteoblast deficiency. Blood. 2004; 103:3258-3264. [PubMed: 14726388]

87. Taichman RS, Reilly MJ, Emerson SG. Human osteoblasts support human hematopoietic progenitor cells in vitro bone marrow cultures. Blood. 1996; 87:518-24. [PubMed: 8555473]

88. Nilsson SK, et al. Osteopontin, a key component of the hematopoietic stem cell niche and regulator of primitive hematopoietic progenitor cells. Blood. 2005; 106:1232-9. [PubMed: 15845900]

89. Stier $\mathrm{S}$, et al. Osteopontin is a hematopoietic stem cell niche component that negatively regulates stem cell pool size. J Exp Med. 2005; 201:1781-91. [PubMed: 15928197]

90. Haug JS, et al. N-cadherin expression level distinguishes reserved versus primed states of hematopoietic stem cells. Cell Stem Cell. 2008; 2:367-79. [PubMed: 18397756]

91. Fleming $\mathrm{H}$, et al. Wnt signaling in the niche enforces hematopoietic stem cell quiescence and is necessary to preserve self-renewal in vivo. Cell Stem Cell. 2008; 2:274-83. [PubMed: 18371452] 
92. Hosokawa $\mathrm{K}$, et al. Cadherin-based adhesion is a potential target for niche manipulation to protect hematopoietic stem cells in adult bone marrow. Cell Stem Cell. 2010; 6:194-8. [PubMed: 20207221]

93. Hosokawa $\mathrm{K}$, et al. Knockdown of N-cadherin suppresses the long-term engraftment of hematopoietic stem cells. Blood. 2010; 116:554-563. [PubMed: 20427705]

94. Morrison SJ, Spradling AC. Stem cells and niches: mechanisms that promote stem cell maintenance throughout life. Cell. 2008; 132:598-611. [PubMed: 18295578]

95. Lapidot T, Dar A, Kollet O. How do stem cells find their way home? Blood. 2005; 106:1901-10. [PubMed: 15890683]

96. Raaijmakers MHGP, et al. Bone progenitor dysfunction induces myelodysplasia and secondary leukaemia. Nature. 2010; 464:852-7. Demonstrates that ablation of micro-RNA processing machinery in osteoblasts can give rise to myelodysplasia and leukaemia. [PubMed: 20305640]

97. Chitteti BR, et al. Impact of interactions of cellular components of the bone marrow microenvironment on hematopoietic stem and progenitor cell function. Blood. 2010; 115:32393248. [PubMed: 20154218]

98. Nakamura Y, et al. Isolation and characterization of endosteal niche cell populations that regulate hematopoietic stem cells. Blood. 2010; 116:1422-32. [PubMed: 20472830]

99. Jung Y, et al. Regulation of SDF-1 (CXCL12) production by osteoblasts; a possible mechanism for stem cell homing. Bone. 2006; 38:497-508. [PubMed: 16337237]

100. Ponomaryov T, et al. Induction of the chemokine stromal-derived factor- 1 following DNA damage improves human stem cell function. J Clin Invest. 2000; 106:1331-9. [PubMed: 11104786]

101. Porter RL, Calvi LM. Communications between bone cells and hematopoietic stem cells. Arch Biochem Biophys. 2008; 473:193-200. [PubMed: 18410740]

102. Lewandowski D, et al. In vivo cellular imaging pinpoints the role of reactive oxygen species in the early steps of adult hematopoietic reconstitution. Blood. 2009; 115:443-52. [PubMed: 19797522]

103. Xie Y, et al. Detection of functional haematopoietic stem cell niche using real-time imaging. Nature. 2009; 457:97-101. References 74-76 and 103 use groundbreaking imaging technology to visualize HSCs in the niche in mice. The authors of references 74, 75, and 103 image murine long bones, and the authors of references 75 and 76 image cells in the bone in vivo. [PubMed: 19052548]

104. Méndez-Ferrer S, et al. Mesenchymal and haematopoietic stem cells form a unique bone marrow niche. Nature. 2010; 466:829-834. Identifies NES ${ }^{+}$MSCs as important niche cells, which are capable of maintaining HSC numbers and function. [PubMed: 20703299]

105. Tzeng YS, et al. Loss of Cxcl12/Sdf-1 in adult mice decreases the quiescent state of hematopoietic stem/progenitor cells and alters the pattern of hematopoietic regeneration after myelosuppression. Blood. 2011; 117:429-439. [PubMed: 20833981]

106. Chen J, et al. Mobilization as a preparative regimen for hematopoietic stem cell transplantation. Blood. 2006; 107:3764-71. [PubMed: 16439683]

107. Katayama Y, et al. Signals from the sympathetic nervous system regulate hematopoietic stem cell egress from bone marrow. Cell. 2006; 124:407-21. [PubMed: 16439213]

108. Wu J, Scadden D, Kronenberg H. Role of the osteoblast lineage in the bone marrow hematopoietic niches. Journal of Bone and Mineral Research. 2009; 24:759-764. [PubMed: 19257832]

109. Zhu J, et al. Osteoblasts support B-lymphocyte commitment and differentiation from hematopoietic stem cells. Blood. 2007; 109:3706-12. [PubMed: 17227831]

110. Omatsu Y, et al. The Essential Functions of Adipo-osteogenic Progenitors as the Hematopoietic Stem and Progenitor Cell Niche. Immunity. 2010; 33:1-13. Identifies the CAR cell as an adipoosteogenic precursor cell capable of serving an HSC niche function, maintaining HSC numbers and function. [PubMed: 20643331]

111. Spiegel A, et al. Catecholaminergic neurotransmitters regulate migration and repopulation of immature human CD34+ cells through Wnt signaling. Nat Immunol. 2007; 8:1123-1131. [PubMed: 17828268] 
112. Spiegel A, Kalinkovich A, Shivtiel S, Kollet O, Lapidot T. Stem Cell Regulation via Dynamic Interactions of the Nervous and Immune Systems with the Microenvironment. Cell Stem Cell. 2008; 3:484-492. [PubMed: 18983964]

113. Butler JM, et al. Endothelial Cells Are Essential for the Self-Renewal and Repopulation of NotchDependent Hematopoietic Stem Cells. Stem Cell. 2010; 6:251-264.

114. Kobayashi H, et al. Angiocrine factors from Akt-activated endothelial cells balance self-renewal and differentiation of haematopoietic stem cells. Nature Cell Biology. 2010; 12:1046-1056.

115. Hooper AT, et al. Engraftment and Reconstitution of Hematopoiesis Is Dependent on VEGFR2Mediated Regeneration of Sinusoidal Endothelial Cells. Stem Cell. 2009; 4:263-274.

116. Cao JJ, Sun L, Gao H. Diet-induced obesity alters bone remodeling leading to decreased femoral trabecular bone mass in mice. Annals of the New York Academy of Sciences. 2010; 1192:292297. [PubMed: 20392249]

117. Rosen CJ, Ackert-Bicknell C, Rodriguez JP, Pino AM. Marrow fat and the bone microenvironment: developmental, functional, and pathological implications. Crit Rev Eukaryot Gene Expr. 2009; 19:109-24. [PubMed: 19392647]

118. Halade GV, Rahman MM, Williams PJ, Fernandes G. High fat diet-induced animal model of ageassociated obesity and osteoporosis. The Journal of Nutritional Biochemistry. 2010; 21:1162-9. [PubMed: 20149618]

119. Casamassima F, et al. Hematopoietic bone marrow recovery after radiation therapy: MRI evaluation. Blood. 1989; 73:1677-81. [PubMed: 2713500]

120. Bredella MA, et al. Vertebral bone marrow fat is positively associated with visceral fat and inversely associated with IGF-1 in obese women. Obesity (Silver Spring). 2011; 19:49-53. [PubMed: 20467419]

121. Naveiras $\mathrm{O}$, et al. Bone-marrow adipocytes as negative regulators of the haematopoietic microenvironment. Nature. 2009; 460:259-263. Indicates a negative influence of bone marrow adipocytes on HSC function. [PubMed: 19516257]

122. Claycombe K, King LE, Fraker PJ. A role for leptin in sustaining lymphopoiesis and myelopoiesis. Proceedings of the National Academy of Sciences. 2008; 105:2017-2021.

123. Pietramaggiori G, et al. Improved Cutaneous Healing in Diabetic Mice Exposed to Healthy Peripheral. Circulation. 2009; 129:2265-2274.

124. Belaid-Choucair Z, et al. Human Bone Marrow Adipocytes Block Granulopoiesis Through Neuropilin-1-Induced Granulocyte Colony-Stimulating Factor Inhibition. Stem Cells. 2008; 26:1556-1564. [PubMed: 18388301]

125. Lane SW, et al. The Apcmin mouse has altered hematopoietic stem cell function and provides a model for MPD/MDS. Blood. 2010; 115:3489-3497. Demonstrates that expression of a hypomorphic allele of APC causes myelodysplastic/myeloproliferative disease (MDS/MPD) in an HSC-extrinsic fashion. [PubMed: 20197553]

126. Walkley $\mathrm{C}$, et al. A microenvironment-induced myeloproliferative syndrome caused by retinoic acid receptor gamma deficiency. Cell. 2007; 129:1097-110. [PubMed: 17574023]

127. Walkley CR, Shea JM, Sims NA, Purton LE, Orkin SH. Rb regulates interactions between hematopoietic stem cells and their bone marrow microenvironment. Cell. 2007; 129:1081-1095. [PubMed: 17574022]

128. Sudo K, Ema H, Morita Y, Nakauchi H. Age-associated characteristics of murine hematopoietic stem cells. J Exp Med. 2000; 192:1273-80. [PubMed: 11067876]

129. de Haan G, Nijhof W, Van Zant G. Mouse strain-dependent changes in frequency and proliferation of hematopoietic stem cells during aging: correlation between lifespan and cycling activity. Blood. 1997; 89:1543-50. [PubMed: 9057635]

130. Dykstra B, Haan G. Hematopoietic stem cell aging and self-renewal. Cell Tissue Res. 2008; 331:91-101. [PubMed: 18008087]

131. Rossi DJ, et al. Cell intrinsic alterations underlie hematopoietic stem cell aging. Proc Natl Acad Sci USA. 2005; 102:9194-9. [PubMed: 15967997]

132. Liang Y, Van Zant G, Szilvassy SJ. Effects of aging on the homing and engraftment of murine hematopoietic stem and progenitor cells. Blood. 2005; 106:1479-87. [PubMed: 15827136] 
133. Wagner W, Horn P, Bork S, Ho AD. Aging of hematopoietic stem cells is regulated by the stem cell niche. Experimental Gerontology. 2008; 43:974-980. [PubMed: 18504082]

134. Chen C, Liu Y, Liu Y, Zheng P. mTOR Regulation and Therapeutic Rejuvenation of Aging Hematopoietic Stem Cells. Science Signaling. 2009; 2:ra75-ra75. Shows that increased expression of mTOR in HSCs from old mice is responsible for the phenotypic and functional changes in hematopoiesis seen in aging and that forced upregulation of mTOR in young HSCs makes them assume an 'aged' phenotype. [PubMed: 19934433]

135. Wang W, et al. Proteomic analysis of interstitial fluid in bone marrow identified that peroxiredoxin 2 regulates $\mathrm{H}(2) \mathrm{O}(2)$ level of bone marrow during aging. J Proteome Res. 2010; 9:3812-9. [PubMed: 20568815]

136. Milyavsky M, et al. A Distinctive DNA Damage Response in Human Hematopoietic Stem Cells Reveals an Apoptosis-Independent Role for p53 in Self-Renewal. Stem Cell. 2010; 7:1-12.

137. Mohrin M, et al. Hematopoietic Stem Cell Quiescence Promotes Error-Prone DNA Repair and Mutagenesis. Stem Cell. 2010:1-12.

138. Stevens SK, Moore SG, Kaplan ID. Early and late bone-marrow changes after irradiation: MR evaluation. AJR Am J Roentgenol. 1990; 154:745-50. [PubMed: 2107669]

139. Dominici M, et al. Restoration and reversible expansion of the osteoblastic hematopoietic stem cell niche after marrow radioablation. Blood. 2009; 114:2333-43. [PubMed: 19433859]

140. Lichtman MA. Obesity and the Risk for a Hematological Malignancy: Leukemia, Lymphoma, or Myeloma. Oncologist. 2010; 15:1083-1101. [PubMed: 20930095]

141. Busik JV, et al. Diabetic retinopathy is associated with bone marrow neuropathy and a depressed peripheral clock. Journal of Experimental Medicine. 2009; 206:2897-2906. [PubMed: 19934019]

142. Song J, et al. An in vivo model to study and manipulate the hematopoietic stem cell niche. Blood. 2010; 115:2592-2600. [PubMed: 20110425]

143. Vunjak-Novakovic G, Scadden David T. Biomimetic Platforms for Human Stem Cell Research. Cell Stem Cell. 2011; 8:252-261. [PubMed: 21362565]

144. McNiece I, Harrington J, Turney J, Kellner J, Shpall EJ. Ex vivo expansion of cord blood mononuclear cells on mesenchymal stem cells. Cytotherapy. 2004; 6:311-7. [PubMed: 16146883]

145. Delaney C, et al. Notch-mediated expansion of human cord blood progenitor cells capable of rapid myeloid reconstitution. Nature Medicine. 2010; 16:232-236. Demonstrates that UCB HSCs can be expanded ex vivo using engineered Notch ligands, and that expanded HSCs can successfully be used in clinical bone marrow transplantation.

146. Lutolf MP, Gilbert PM, Blau HM. Designing materials to direct stem-cell fate. Nature. 2009; 462:433-441. [PubMed: 19940913]

147. Goessling W, et al. Genetic Interaction of PGE2 and Wnt Signaling Regulates Developmental Specification of Stem Cells and Regeneration. Cell. 2009; 136:1136-1147. [PubMed: 19303855]

148. North TE, Goessling W. NOTCHing an Arrow at Cord Blood: Translating Stem Cell Knowledge into Clinical Practice. Stem Cell. 2010; 6:186-187.

149. Tesio M, et al. Enhanced c-Met activity promotes G-CSF-induced mobilization of hematopoietic progenitor cells via ROS signaling. Blood. 2011; 117:419-428. [PubMed: 20585044] 


\section{Online Summary}

- Haematopoietic stem cells (HSCs) are maintained in specialized microenvironments known as "niches," which are composed of complex cellular and acellular components. Recent advances have contributed significantly to our understanding of what the niche is and how it changes during development, aging, and disease.

- In particular, powerful new imaging techniques permit the direct observation of HSCs in their niches. These techniques provide novel insights concerning the emergence of HSCs from the dorsal aorta in fetal haematopoiesis, as well as the associations between HSCs and niche components in adult haematopoiesis.

- Previous conceptions of niches as static, anatomically-defined bone marrow microenvironments consisting predominantly of one cell type are being challenged. Increasingly, it is becoming clear that the niche is an anatomically fluid and very dynamic environment, wherein multiple physical and cellular inputs are integrated by HSCs.

- Physical inputs known to be important in haematopoiesis include oxygen tension, calcium concentration, shear, and mechanical support. Identified bone marrow niche cells include osteoblasts, vascular endothelial cells, mesenchymal stem cells, CXCL12-abundant reticular cells, neural cells, and adipocytes.

- Recent work demonstrates that dysfunctional haematopoiesis, such as myelodysplasia and leukaemia, can result from defects in the microenvironment alone, without genetic perturbation of HSCs. This indicates that strategies for correcting hematopoietic diseases that target only the HSC may be insufficient or incomplete.

- Many current clinical trials are exploiting our expanding knowledge of niche biology to improve haematopoietic stem cell transplantation. At present, such studies are largely restricted to targeting relevant niche pathways to effect HSC expansion ex vivo before transplantation; however, future clinical trials will likely allow more directed manipulation of haematopoiesis in vivo. 


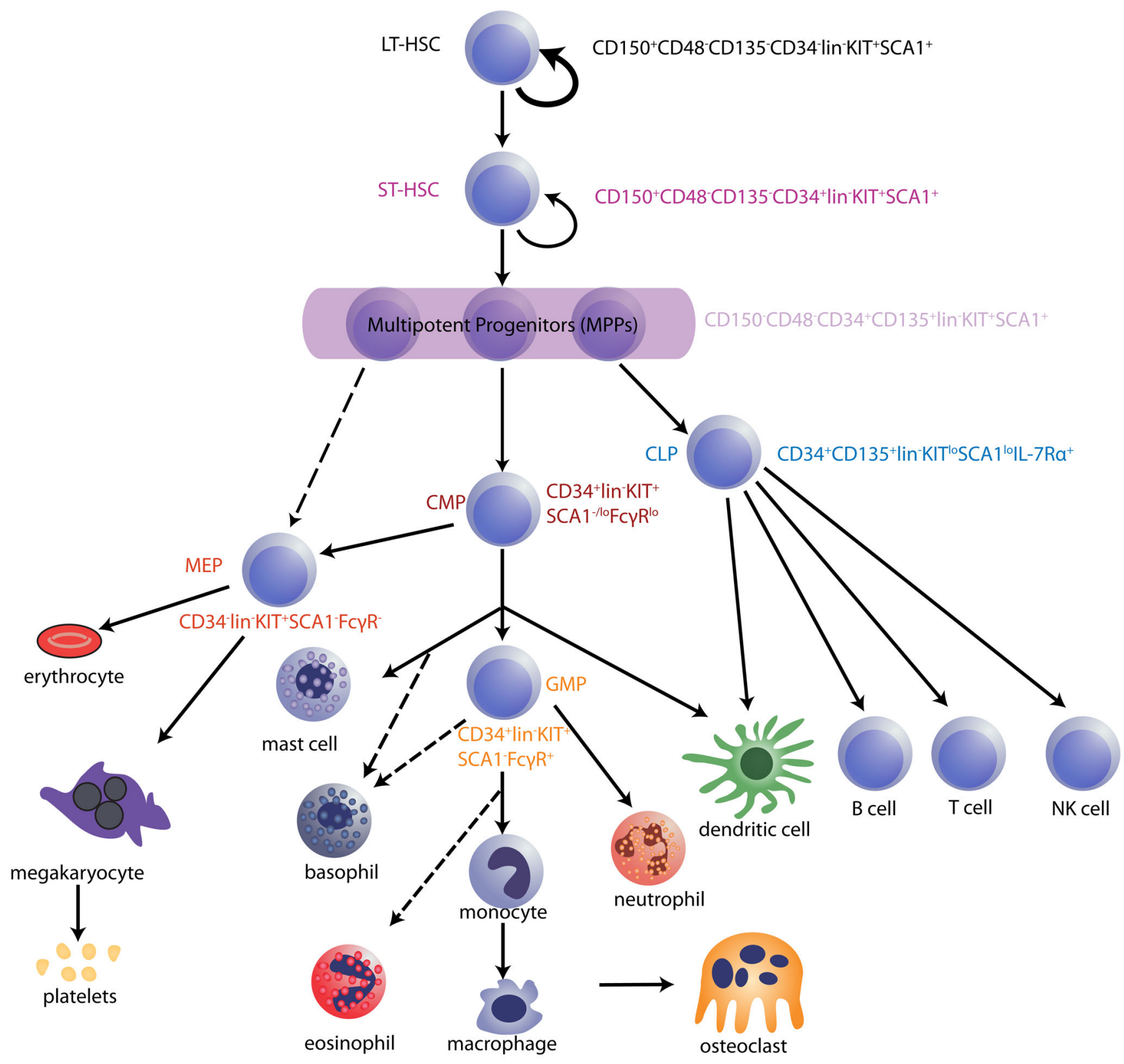

Figure 1. Hierarchical model of haematopoiesis in the adult bone marrow

All haematopoietic cells ultimately derive from a small population of haematopoietic stem cells (HSCs), which is separable into at least two subsets: long-term reconstituting HSCs (LT-HSCs) and short-term reconstituting HSCs (ST-HSCs). LT-HSCs maintain self-renewal and multi-lineage differentiation potential throughout life (represented by the bold arrow). ST-HSCs derive from LT-HSCs and, although they maintain multipotency, they exhibit more-limited self-renewal potential. Further differentiation of ST-HSCs generates multipotent progenitors (MPPs) and then oligopotent progenitors, which are marked with asterisks. Haematopoietic progenitor cells lose their differentiation potential in a stepwise fashion until they eventually generate all of the mature cells of the blood system (these are depicted at the bottom of the schematic). Several potentially distinct subsets of MPPs have 
been described, but MPPs are shown here as a condensed population for simplicity. Lineagecommitted oligopotent progenitors derived from MPPs include the common lymphoid progenitor (CLP), common myeloid progenitor (CMP), megakaryocyte erythrocyte progenitor (MEP) and granulocyte-monocyte progenitor (GMP) populations. HSC and progenitor populations can be discriminated by flow cytometry, using antibodies that recognize unique combinations of cell surface markers. Some commonly used profiles for identifying these cells are shown adjacent to the HSC and progenitor populations. Dotted arrows denote a proposed lineal connection. CD135, also known as FLK2 and FLT3; IL-7R, interleukin-7 receptor; lin, lineage markers (which are a combination of markers found on mature blood cells but not HSCs or progenitors); NK, natural killer; SCA1, surface cell antigen 1 . 

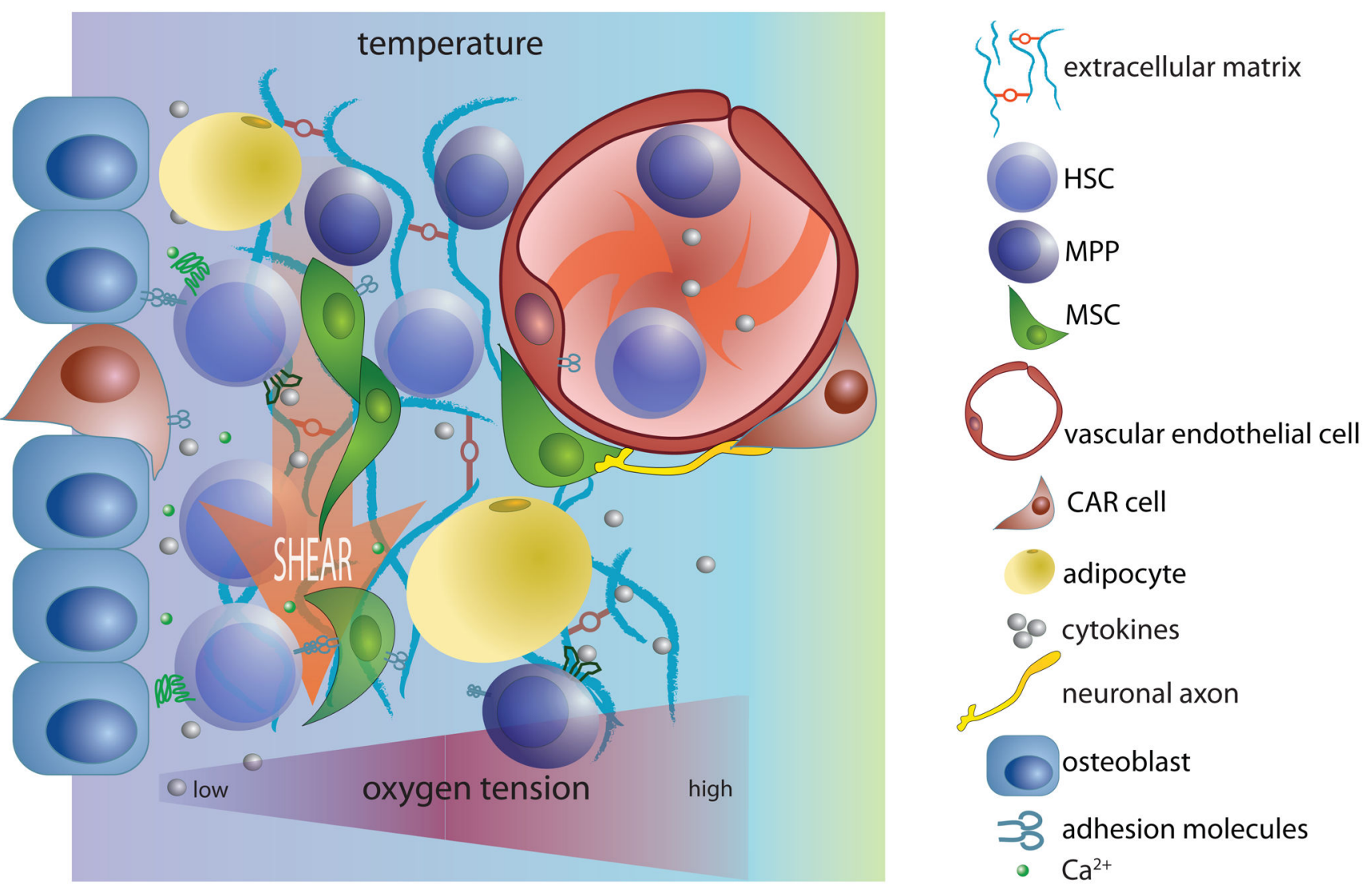

Figure 2. Components of a hypothetical HSC 'niche'

'Niches' provide physical support, soluble factors and cell-mediated interactions to maintain and regulate the function of haematopoietic stem cells (HSCs). In addition, they can provide physical conditions that are conducive to stem cell renewal and differentiation. This schematic represents many of the factors that have been shown recently to be important in the bone marrow haematopoietic niche. Because cytokines and cell surface adhesion molecules have been reviewed extensively elsewhere ${ }^{33,34,44,59,66,67}$ they are depicted only generally in this schematic. Instead, this figure emphasizes the many distinct cell populations that contribute to HSC regulation by the niche, and the critical chemical, physical and mechanical signals that can modulate HSC behaviour, including temperature, shear forces, oxygen tension and monoatomic ions, such as $\mathrm{Ca} 2+$. This image is not intended to provide a comprehensive illustration of relevant niche factors. CAR, CXCL12-abundant reticular; GPCR, G protein-coupled receptor; MPP, multipotent progenitor; MSC, mesenchymal stem cell; RTK, receptor Tyr kinase. 


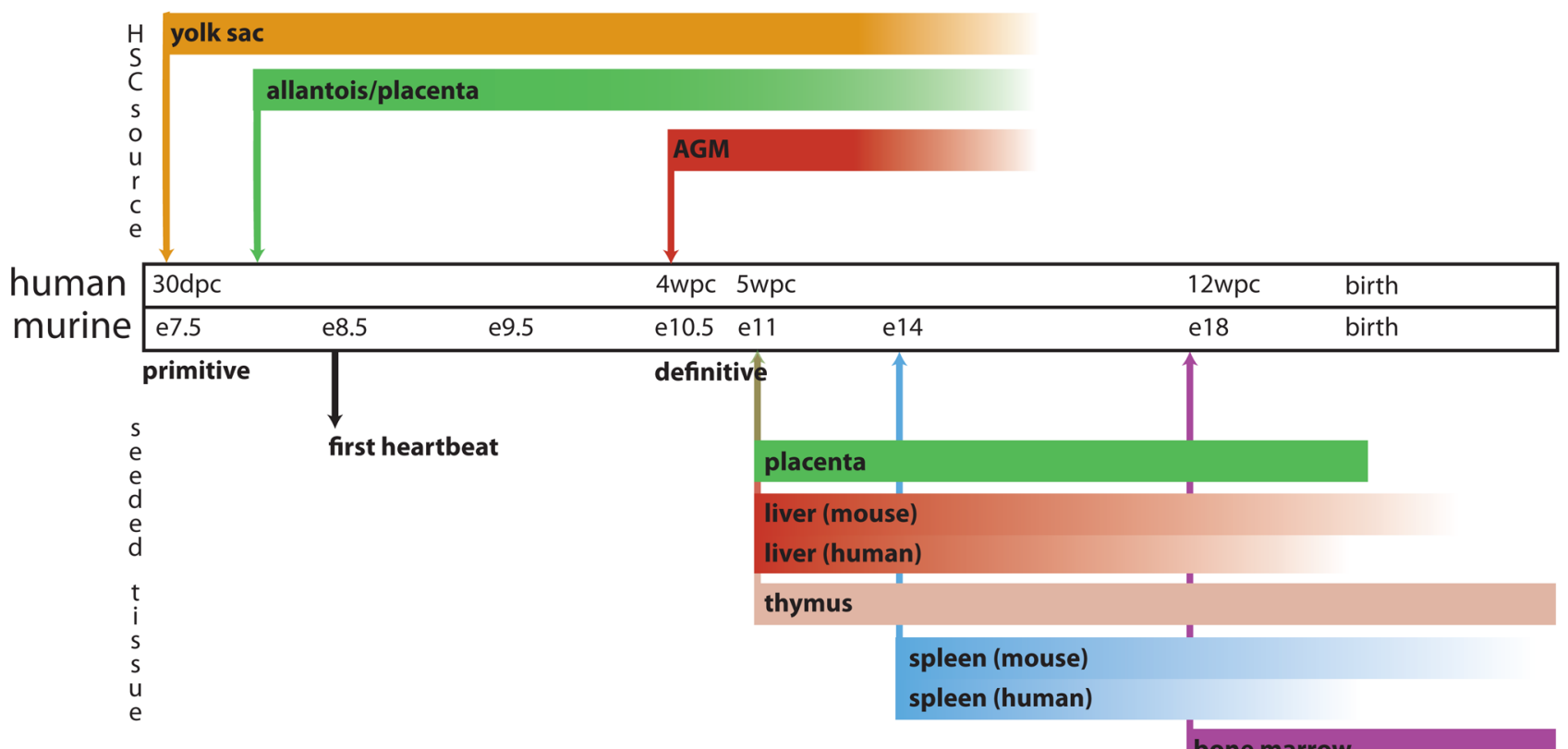

Figure 3. Timeline of haematopoietic development in mice and humans

Haematopoiesis initiates at multiple times and locations during mammalian development and involves both a primitive wave and a definitive wave. The primitive wave is dedicated primarily to the rapid production of erythroid progenitors, whereas multipotent haematopoietic stem cells (HSCs), which maintain haematopoiesis for life, are born during the definitive wave. This figure depicts the anatomical locations from which HSCs and progenitor cells emerge and to which these cells traffic during embryonic and fetal life in mice and in humans. De novo sources of HSC specification are indicated above the timeline and organs subsequently seeded by HSCs born at these locations are depicted below. Arrows denote the earliest timepoints of haematopoiesis in the associated tissue or organ; bars represent the duration of haematopoiesis in that tissue or organ. Bars fade as haematopoiesis wanes. For tissues or organs in which timing differs between mouse and human, two bars are shown; where timing is analogous, one bar is shown. AGM; aorta-gonad-mesonephros; dpc, days post-conception; E, embryonic day; wpc, weeks post-conception. Figure is modified, with permission, from REF.17@(2008) Macmillan Publishers Ltd. All rights reserved. 


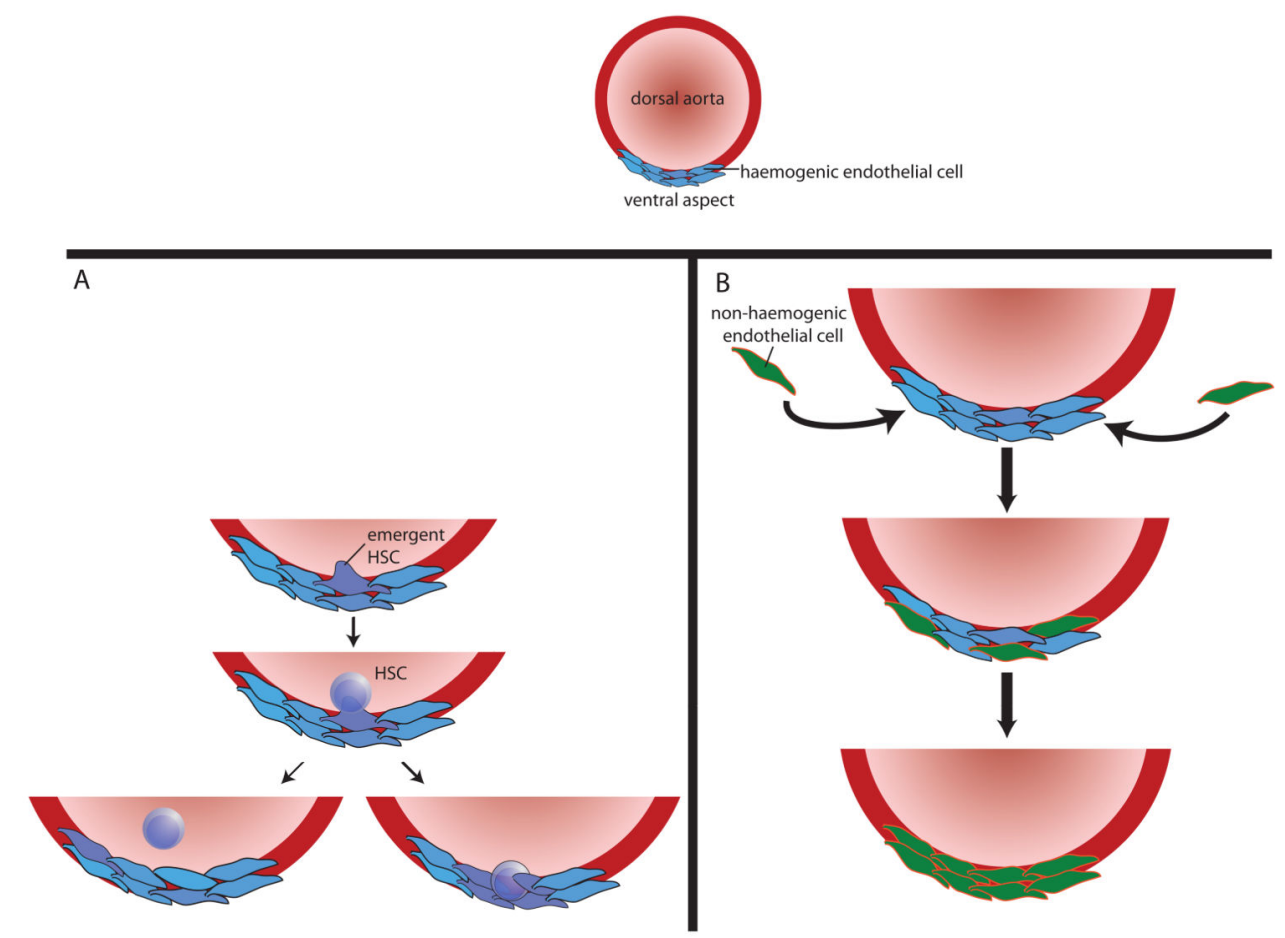

Figure 4. Definitive fetal haematopoiesis in the AGM

a) during definitive fetal haematopoiesis, haematopoietic stem cells (HSCs) emerge directly from haemogenic endothelium (blue) in the ventral aspect of the dorsal aorta. $\mathbf{b} \mid$ Emergent HSCs appear to arise directly from endothelial cells (purple); they then either enter the circulation (bottom left) or remain embedded in the endothelium (bottom right). In the case of HSCs that remain in the endothelium, haemogenic endothelial cells appear to be able to act as 'niche' cells. It is not known what signals determine whether emergent HSCs enter the circulation or remain in situ. However, the pulsatile nature of arterial circulation, coupled with the finding that shear stress upregulates Runxl (a transcription factor known to be critical for developmental haematopoiesis) in fetal HSCs, suggests that this process may be regulated, at least in part, by blood flow. c| Over time, haemogenic endothelium is replaced by non-haemogenic endothelial cells (green) that migrate from periaortic somites, remodelling the haematopoietic niche so that it no longer supports the emergence or maintenance of HSCs. The signals that mediate this migration are unclear. AGM, aortagonad-mesonephros. 


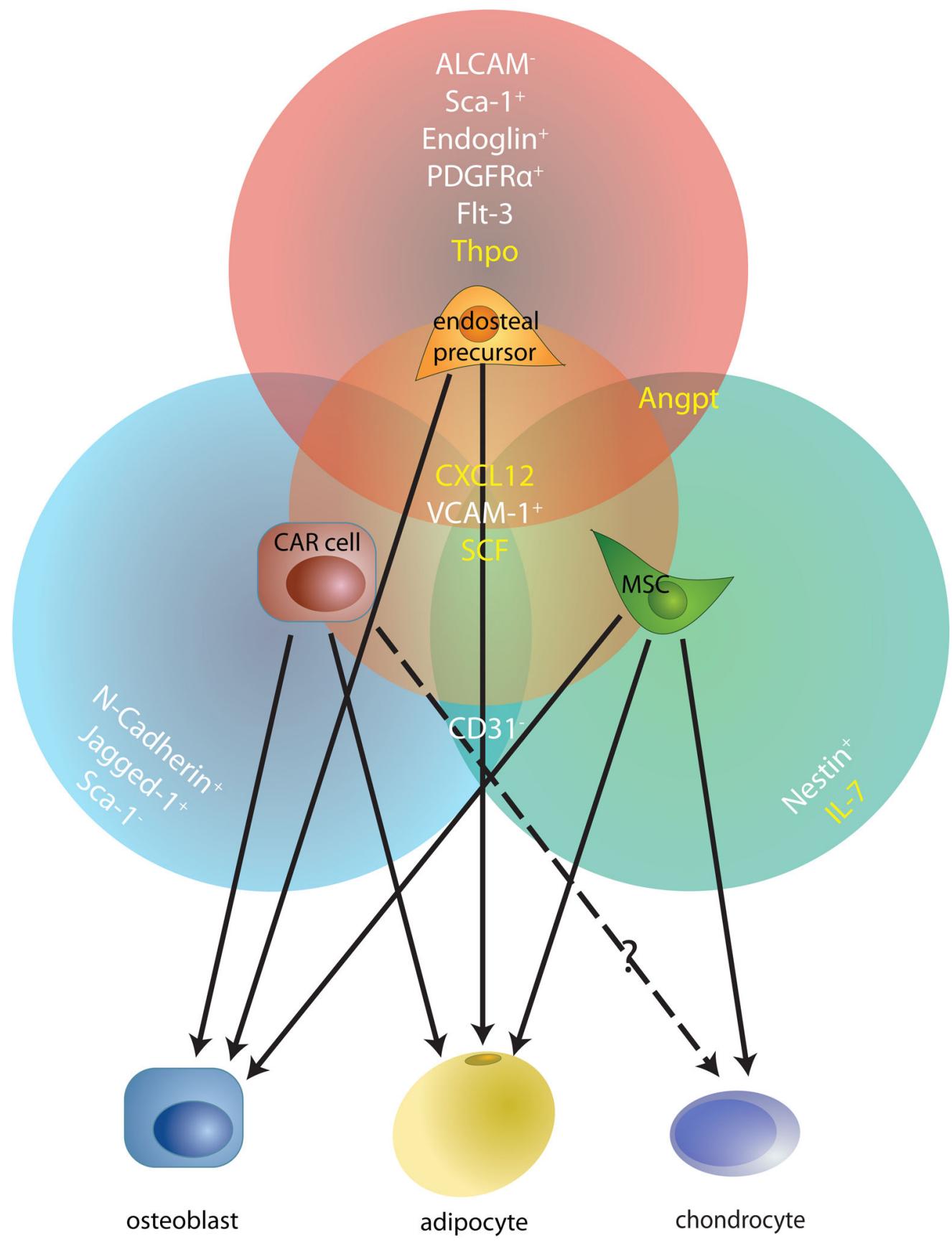

Figure 5. Stromal cells in the bone marrow 'niche'

Many recently-identified mesenchymal cell types in the bone marrow microenvironment appear to overlap significantly with one another, based on their cell surface marker phenotypes, gene expression profiles and functional properties. This modified Venn diagram highlights three such cells - CXCL12-abundant reticular (CAR) cells ${ }^{37}$, mesenchymal stem cells (MSCs) ${ }^{104}$ and surface cell antigen 1-expressing $\left(\mathrm{Sca}^{+}\right.$) bone-lining cells ${ }^{98}$ (labelled endosteal precursor). The factors secreted by these cells that can regulate HSCs are shown in yellow and the cell surface markers that they express are listed in white. The cell types into 
which these mesenchymal cells can differentiate into, determined largely by in vitro differentiation assays, are indicated by the solid arrows. It is unclear whether CAR cells can differentiate into chondrocytes (dotted arrow). ALCAM, activated leukocyte cell adhesion molecule; ANGPT, angiopoietin; CD135, also known as FLK2 and FLT3; CXCL12, CXC chemokine ligand 12; ENG, endoglin; IL-7, interleukin-7; JAG1, Jagged1; N-cadherin, neural cadherin; NES, nestin; PDGFRa, platelet-derived growth factor receptor-a;

PECAM1, platelet endothelial cell adhesion molecule 1; SCF, stem cell factor; TPO, thrombopoietin; VCAM1, vascular adhesion molecule 1. 